\title{
FISCAL SUSTAINABILITY
} AND POLICY IMPLICATIONS FOR THE EURO AREA

by Fabrizio Balassone, Jorge Cunha, Geert Langenus, Bernhard Manzke, Jeanne Pavot, Doris Prammer and Pietro Tommasino 


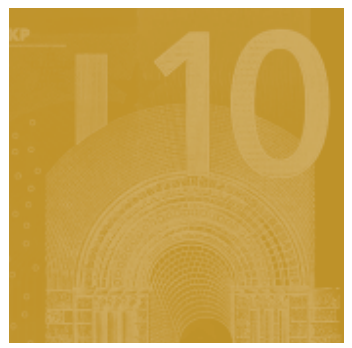

\title{
WORKING PAPER SERIES
}

NO 994 I JANUARY 2009

\author{
FISCAL SUSTAINABILITY \\ AND POLICY IMPLICATIONS \\ FOR THE EURO AREA'
}

\author{
by Fabrizio Balassone ${ }^{2}$, Jorge Cunha ${ }^{3}$, \\ Geert Langenus ${ }^{4}$, Bernhard Manzke ${ }^{5}$, \\ Jeanne Pavot ${ }^{6}$, Doris Prammer ${ }^{7}$ \\ and Pietro Tommasino ${ }^{2}$
}

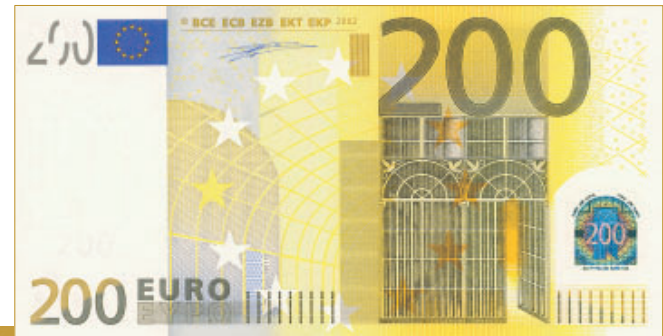

In 2009 all ECB

1 The views expressed in this paper are those of the authors and do not necessarily reflect the views of their institutions or the European Central Bank The authors would like to thank Maximilian Baylor, Louis Bê Duc, Didier Blanchet, Francisco de Castro Fernández, Krisztina Karagyozova, Helvi Kinnunen, Nadine Leiner-Killinger, Richard Morris, Olegs Tkacevs, Kris Van Cauter, Karsten Wendorff and several colleagues from the European System of Central Banks for very helpful comments and discussions and Muriel Bouchet, Cláudia Rodrigues Braz, Francisco de Castro Fernández, Helvi Kinnunen, Nadine Leiner-Killinger and Diarmaid Smyth for their contributions to the country fiches in the Annex.

2 Banca d'Italia, Via Nazionale91, I-00184 Rome, Italy; e-mail: fabrizio.balassone@bancaditalia.it, pietro.tommasino@bancaditalia.it 3 Banco de Portugal, 148, Rua do Comercio, P-II0I Lisbon Codex, Portugal; e-mail: jmmccunha@bportugal.pt 4 Corresponding author: National Bank of Belgium, Boulevard de Berlaimont 14, B-1000 Brussels, Belgium; e-mail: geert.langenus@nbb.be 5 Deutsche Bundesbank, Wilhelm-Epstein-Strasse 14, D-6043I Frankfurt am Main, Germany; e-mail: bernhard.manzke@bundesbank.de 6 Banque de France, 39, rue Croix-des-Petits-Champs, F-75049 Paris Cedex 0I, France; e-mail: jeanne.pavot@banque-france.fr 


\section{(C) European Central Bank, 2009}

\section{Address}

Kaiserstrasse 29

60311 Frankfurt am Main, Germany

\section{Postal address}

Postfach 160319

60066 Frankfurt am Main, Germany

\section{Telephone}

+496913440

Website

http://www.ecb.europa.eu

Fax

+496913446000

\section{All rights reserved.}

Any reproduction, publication and reprint in the form of a different publication, whether printed or produced electronically, in whole or in part, is permitted only with the explicit written authorisation of the ECB or the author(s).

The views expressed in this paper do not necessarily reflect those of the European Central Bank

The statement of purpose for the ECB Working Paper Series is available from the ECB website, http://www.ecb.europa. eu/pub/scientific/wps/date/html/index. en.html

ISSN 1725-2806 (online) 


\section{CONTENTS}

Abstract

Non-technical summary

Introduction

1 Age-related expenditure projections by the Working Group on Ageing Populations: a risk- assessment exercise

1.1 The projections of the Working Group on Ageing Populations: a bird's eye view

1.2 The AWG projections for ageing-related spending in the euro area: main results

1.3 The AWG projections for ageing-related spending in the euro area: main assumptions

1.4 Risk assessment

1.5 Factoring the risks into the projections

1.6 Conclusions and limitations of our work

2 Ageing and fiscal sustainability

2.1 Fiscal sustainability and deficit-debt dynamics

2.2 Measurement of sustainability gaps

3 Intergenerational distribution effects of alternative adjustment strategies

3.1 Introduction

3.2 Methodology and data

3.3 Results: Comparing the lifetime net tax burden of alternative adjustment strategies for different cohorts

4 Conclusion

List of references

European Central Bank Working Paper Series 


\begin{abstract}
In this paper we examine the sustainability of euro area public finances against the backdrop of population ageing. We critically assess the widely used projections of the Working Group on Ageing Populations (AWG) of the EU's Economic Policy Committee and argue that ageing costs may be higher than projected in the AWG reference scenario. Taking into account adjusted headline estimates for ageing costs, largely based upon the sensitivity analysis carried out by the AWG, we consider alternative indicators to quantify sustainability gaps for euro area countries. With respect to the policy implications, we assess the appropriateness of different budgetary strategies to restore fiscal sustainability taking into account intergenerational equity. Our stylised analysis based upon the lifetime contribution to the government's primary balance of different generations suggests that an important degree of pre-funding of the ageing costs is necessary to avoid shifting the burden of adjustment in a disproportionate way to future generations. For many euro area countries this implies that the medium-term targets defined in the context of the revised stability and growth pact would ideally need to be revised upwards to significant surpluses.
\end{abstract}

Keywords: population ageing, fiscal sustainability, generational accounting, mediumterm objectives for fiscal policy

JEL Classification: H55, H60 


\section{Non-technical summary}

Population ageing poses important challenges for policymakers in the coming decades. Increasing outlays for pension, health and elderly care systems will weigh on government budgets while economic growth is projected to decline due to the gradually decreasing population of working age. At the Stockholm European Council in 2001 a three-pronged strategy was formulated to deal with those challenges. It consists of structural reforms to pension and care systems, measures to increase employment and economic growth and fiscal consolidation. In this paper we focus on the latter element and we examine the issue of fiscal sustainability in euro area countries, i.e. the extent to which current fiscal policies can be continued or will have to be adjusted.

We first carry out a critical assessment of the widely-used estimates of the budgetary impact of population ageing by the European Policy Committee's Working Group on Population Ageing. According to this Working Group's most recent estimates ageing would worsen budget balances by around $4.3 \%$ of GDP in the $2010-2050$ period in the eleven countries that initially formed the euro area in 1999. However, such long-term projections are obviously surrounded with significant uncertainties. Using plausible alternative estimates for key parameters in the Working Group's projections, largely based upon sensitivity analyses carried out by this Working Group, we find that ageing costs in the $2010-2050$ period may be 1 percentage point higher.

Against this background, we look at a range of fiscal sustainability indicators and calculate sustainability gaps taking into account the modified ageing costs. We find that, of all the countries considered in this paper, public finances currently only appear to be sustainable in Finland. All other countries will have to adjust their fiscal policies sooner or later. The exact size of the sustainability gaps differs according to the indicator chosen but the ranking of the countries is more robust. The required adjustment effort is much smaller for countries that have recently implemented important structural reforms to their pension systems such as Germany, Austria and Italy.

Sustainability indicators such as the ones considered in this paper typically measure the size of an 'early' adjustment effort to restore fiscal sustainability. In many cases, this early adjustment effort would imply very important consolidation measures in the coming years. In this paper we propose to analyse the appropriateness of such a budgetary strategy on the basis of an intergenerational equity criterion. The method that is used to make this criterion operational is close to a classical generational accounting approach but differs from it in a number of specific aspects. By attributing government revenue and primary expenditure to different age cohorts, we calculate a 'net tax burden' for different generations. We then compare the evolution of this net tax burden for two different budgetary strategies, an early adjustment effort aimed at restoring fiscal sustainability in the coming years already and a more gradual fiscal adjustment spread over the 2010-2050 period. We show for three euro area countries - Belgium, Germany and France that the earlier fiscal adjustment effort leads to a somewhat flatter profile for the net tax burden across age cohorts: the burden is higher for younger and future generations but the increase is generally less steep than under the more gradual adjustment effort. Hence, an earlier fiscal adjustment, i.e. 'pre-funding' (a large part of) the ageing costs via fiscal consolidation in the coming years can in our view be considered more equitable.

Our calculations of the fiscal burden across age cohorts are partly based upon a number of simplifying assumptions (e.g. with respect to the age profiles for specific government revenue and expenditure items). However, sensitivity analysis shows that the main result - a pre-funding approach is more equitable than a gradual fiscal adjustment - is quite robust to changes in these assumptions. 
While the paper does not provide any insights on which policy mix, e.g. structural reforms vs. budgetary pre-funding, is the optimal response to population ageing, its main conclusion seems relevant against the background of the developments in the EU fiscal rules. The ECOFIN Council has indeed recently indicated that long-term fiscal sustainability, notably the future impact of ageing, is to be better taken into account in the definition of the medium-term objectives for fiscal policy introduced in the context of the revised stability and growth pact. In this connection, concerns for intergenerational equity could play a role and could be made operational along the lines suggested here. If our tentative conclusions were confirmed and if no further cost-cutting reforms to pension and care systems are implemented, an upward revision of the medium-term objectives to significant surpluses may then be warranted for many EU Member States. 


\section{Introduction}

Populations are ageing rapidly in nearly all EU Member States, due to gradually increasing life expectancy, the baby-boom baby-bust cycle observed in the second half of the last century and a long-run trend towards low birth rates. Awareness of the potentially very important macroeconomic and budgetary implications of these demographic changes has increased in recent years. Authorities now routinely try to gauge the impact of population ageing on the sustainability of public finances and increasingly take into account the findings of these studies when defining their economic policies. In this connection, a three-pronged strategy was formulated at the Stockholm European Council in 2001. It entails a rapid reduction of public debt, an increase in employment and productivity and reforms to existing pension, health and long-term care systems. Policy responses should obviously comply with all relevant EU fiscal rules and be tailored to restore fiscal sustainability in a timely manner.

With respect to the budgetary pillar of that three-pronged strategy and in accordance with the Conclusions of the ECOFIN Council of 9 October 2007, long-term fiscal sustainability, notably the future impact of ageing, is to be better taken into account in the definition of the mediumterm objectives (MTOs) for fiscal policy introduced in the context of the revised stability and growth pact. One of the key questions in this respect is to what extent future ageing-related expenditure should be pre-funded by attaining high primary surpluses in the coming years.

This paper does not provide any insights on which policy mix, e.g. structural reforms vs. budgetary pre-funding, is the optimal response to population ageing. It simply wants to contribute to the debate on the appropriate timing of the budgetary component of the response to population ageing - and the definition of 'ageing-augmented' MTOs in particular - keeping all other things equal. We specifically analyse the relative merits of an 'early' fiscal adjustment (implying a strong fiscal tightening for many countries in the following years) and a more gradual fiscal adjustment. In this connection, we propose to use intergenerational equity as the main criterion and to look into the intergenerational implications of these two stylised strategies on the basis of the lifetime net contribution to the government's primary balance of different cohorts.

The remainder of the paper is organised as follows. The first section assesses the EU-wide projections of the ageing costs used as a benchmark in the current institutional context. This is done on the basis of a detailed analysis for most euro area countries. ${ }^{1}$ On the basis of this assessment, we present alternative estimates of the ageing costs for each of the different countries considered. The second section is devoted to the quantification of the sustainability gaps (taking into account the alternative estimates of the ageing costs). The third section then looks at the intergenerational implications of different adjustment strategies to restore fiscal sustainability along the lines suggested above for a selected group of euro area countries (Belgium, Germany, and France). The final section presents some concluding remarks.

1 Individual country fiches are not included in the main text of this paper but are made available in an Annex which can be downloaded from http://www.ecb.europa.eu/pub/scientific/wps/date/html/index.en.html or obtained from the authors. 


\section{Age-related expenditure projections by the Working Group on Ageing Populations: a risk- assessment exercise}

\subsection{The projections of the Working Group on Ageing Populations: a bird's eye view}

From the mid-80s, when it became apparent that Western countries were experiencing major changes in their demographic structure, an increasing number of studies have examined the longterm prospects for public budgets. These studies usually focus on expenditure items which are particularly dependent on the age structure of populations (pensions, health, education). Some studies also develop projections for the primary balance and estimate the adjustment required to ensure budgetary sustainability (usually meaning a stable undiscounted debt to GDP ratio).

International organisations have been at the forefront in the development of the literature. ${ }^{2}$ Their studies allowed cross-country comparison thanks to methodological homogeneity. However, since the reliability of age-related expenditure projections depends on detailed and updated institutional knowledge, the paucity of national projections represented a major drawback. Growing awareness of the impact of population ageing gradually led to a substantial increase in the resources devoted to national long-term expenditure projections. Yet, at the turn of the century, projections for the main age-related expenditure items were available only for a few industrial countries.

Against this background, the age-related expenditure projections by the Working Group on Ageing Populations (AWG) for EU member states come with a unique value added. They are produced in a multilateral setting involving national authorities and an international organisation, thus reconciling as much as possible national detail and cross-country comparability.

The 2006 AWG report covers 25 EU member states and for most of them provides projections for pensions, health care, long-term care, education, and unemployment benefits (EPC and EC, 2006). ${ }^{3}$ The projections reflect the impact of enacted legislation, including provisions already legislated but coming only into force over time. The report is rich in sensitivity analysis.

In the report, the main results under the reference scenario are summarised as follows": "Overall, ageing populations" (are) "projected to lead to increases in public spending in most Member States by 2050 on the basis of current policies, although there is a wide degree of diversity across countries. The following points should be highlighted:

- for the EU15 and the Euro-area as a whole, public spending is projected to increase by about 4 percentage points between 2004 and 2050; [...]

- most of the projected increase in public spending will be on pensions, health care and longterm care. Potential offsetting savings in terms of public spending on education and unemployment benefits are likely to be limited;

- the budgetary impact of ageing in most Member States starts to become apparent as of 2010. However, the largest increases in spending [...] take place between 2020 and 2040"

2 See Heller et al. (1986), Leibfritz et al. (1995), and Franco and Munzi (1997).

3 Countries included are the EU15 (the 12 countries in the euro area at the time of the report - Austria, Belgium, Finland, France, Germany, Greece, Spain, Ireland, Italy, Luxembourg, the Netherlands, and Portugal - plus Denmark, Sweden and the UK) and EU10 (the ten new member states which joined the union before the report was prepared: Cyprus, Czech Republic, Estonia, Hungary, Latvia, Lithuania, Malta, Poland, Slovak Republic, and Slovenia). Not all expenditure items are projected for all countries.

4 EC and EPC, 2006, p. 10. See also the table reproduced later in the main text. 
This paper focuses on the countries that were in the euro area at the time of the AWG report. The assumptions underlying the AWG baseline projections are analysed in detail in this section in order to assess whether the underlying risks are broadly balanced or not. To this end we mostly rely on sensitivity analyses accompanying AWG projections.

The AWG projections encompass five public expenditure items which are likely to be affected by ageing: pensions, health care, long-term care, education and unemployment. Most of these items directly depend on the age structure of populations. Other expenditure items not considered by the AWG, such as family allowances, may also depend on demographics. Certain revenue categories may also be affected by population ageing: ageing-induced shifts in consumption patterns may have an impact on indirect taxes while taxes and social contributions levied on wages obviously depend on the age structure of the population.

\subsection{The $A W G$ projections for ageing-related spending in the euro area: main results}

The AWG projections encompass the 2004-2050 period but we choose to focus on the 20102050 period since the projected change between 2004 and 2010 has in some cases been outdated by new data and most of the expenditure increase occurs after $2010.5^{5}$

\section{Graph 1: Changes in dependency ratios and expenditure ratio (2010-2050)}



Ageing-related spending rises by 4.3 p.p. of GDP on average in the euro area (excluding Greece ${ }^{6}$ ) over the 2010-2050 period in the baseline scenario of the AWG (Table 1.1). Increases range from 1.1 p.p. (Austria) to 8.9 p.p. of GDP (Spain). For most countries, expenditure peaks around 2040. For all countries except Austria and Italy the bulk of the increase comes from pensions. For Italy, this reflects the introduction of a defined-contribution scheme in 1995. In Austria, it is the result of reforms enacted as of 2000 which increased the legal retirement age, linked contributions more

5 Early in 2007 a major social security reform was approved in Portugal. Updated projections, peer-reviewed at the AWG and approved at the EPC in October 2007, are used throughout this paper.

6 Pension and long-term care expenditure data were not provided for Greece in the AWG projection exercise. 
closely to benefits (with actuarial reductions for early pensions) and switched the indexation rule for pensions from wages to prices as of 2006.

There is no clear correlation between projected expenditure increases and expected changes in old-age dependency ratios. Graph 1 shows that Italy and Austria, whose dependency ratios are expected to increase more than average, are the countries where expenditure is projected to grow least. At the same time, the countries where expenditure is projected to grow most (Luxembourg, Spain and Ireland) and by similar amounts (around 8 p.p. of GDP) are characterised by very different expected increases in dependency ratios (from 15 to 40 p.p.). This reflects differences in pension systems rules or maturity and/or in health and long-term care policies.

\subsection{The AWG projections for ageing-related spending in the euro area: main assumptions}

\subsubsection{Demographic assumptions}

The demographic scenario underlying the expenditure projections was prepared by Eurostat. It is based on, though not identical to, the EUROPOP2004 projection released by Eurostat in 2005.7 The fertility rate assumptions are the same as those in the baseline of EUROPOP2004; the assumptions on life expectancy at birth are based on a scenario produced by Eurostat specifically for the AWG; the migration assumptions are the same as those in the baseline of EUROPOP2004 except for Germany, Italy and Spain, where adjustments were made to the level and/or age structure of migrants to incorporate more recent information.

More specifically:

- fertility rates increase over the projection period in all countries except France and Ireland, where small declines are projected for the sake of convergence. Fertility rates remain well below the replacement rate stabilising population size (2.1). Nevertheless, except for France and Ireland, the downward past trends are assumed to be curbed;

- life expectancy at birth is projected to rise further, though at a slower pace than over the 1960-2000 period, when it increased by about eight years in EU countries (three months per annum).

In this scenario population in the euro area will not be much smaller in 2050 , but it will be significantly older: population of working age will decline by 16 percent. This aggregate picture hides wide cross-country variation. The population is projected to fall sharply in Italy and Germany and to increase substantially in France, the Netherlands, Ireland, Belgium and Luxemburg. Changes in the age structure of population are less diverse. Population aged less than 15 years and population of working age (from 15 to 64 years old) will decline in all countries except Ireland and Luxembourg (by 17\% and 16\% respectively, for the euro area). Population aged 65 or more will increase in all countries, with hikes ranging from 17\% to $30 \%$.

7 'EU-25 population rises until 2025, then falls', Eurostat press release 448/2005, 8 April 2005. 


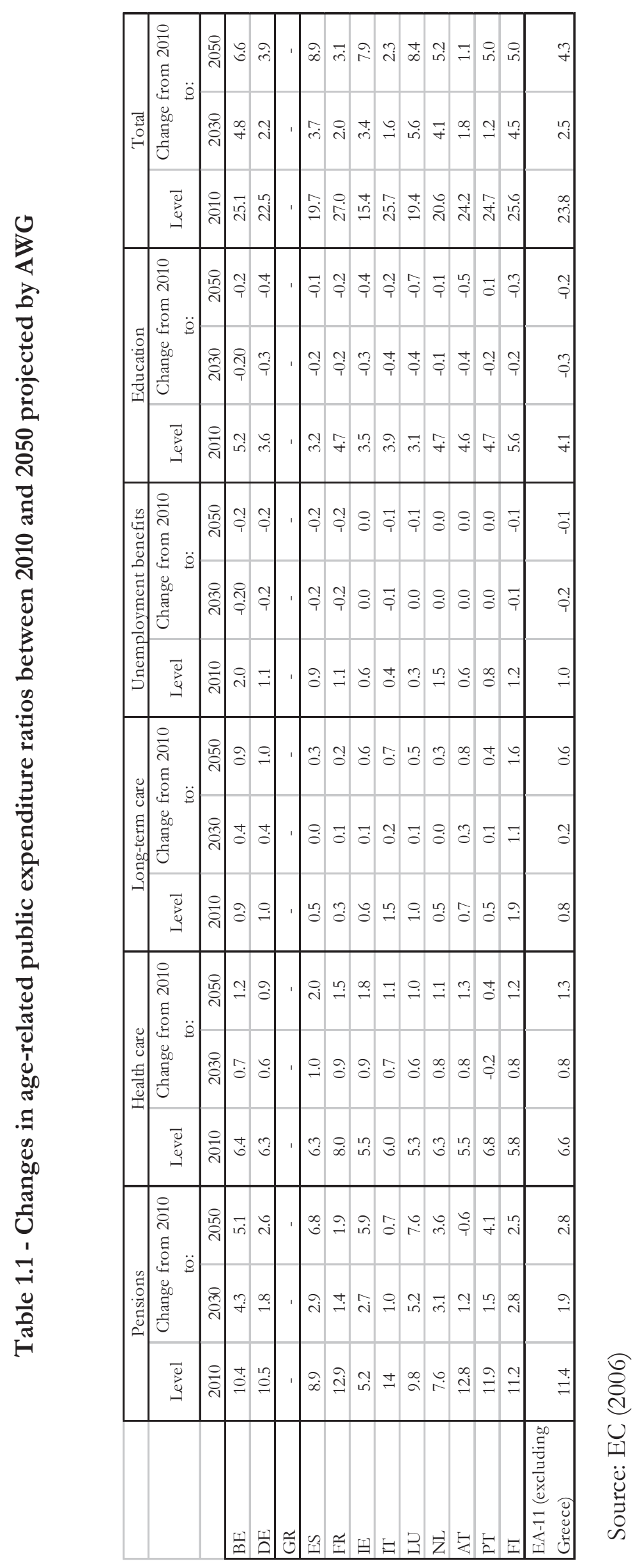




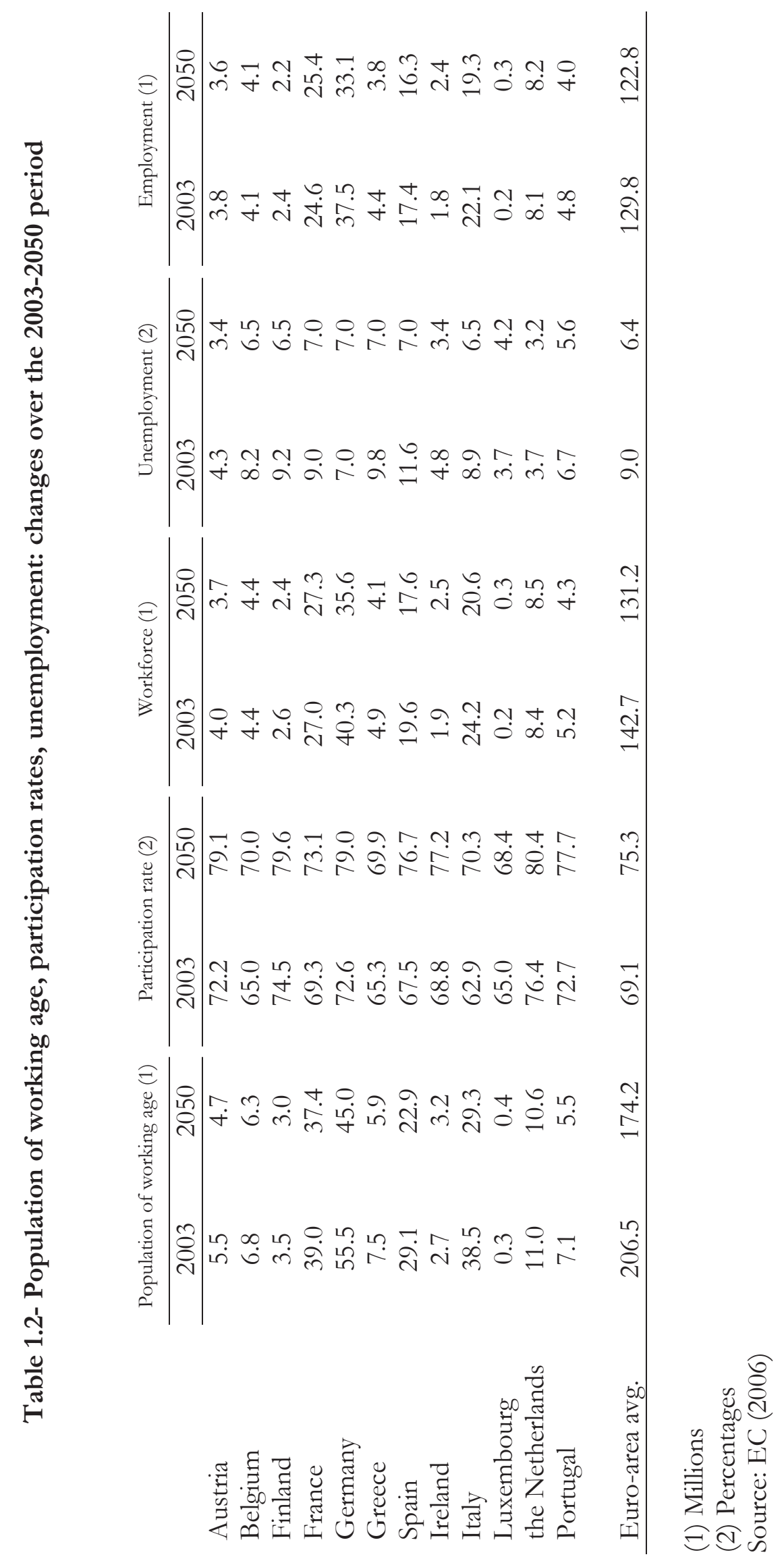




\section{Macroeconomic assumptions}

The participation rate is projected to increase by about 6 p.p. over 2003-2050 in the euro area. As a result, the workforce declines less than population of working age (8\% versus $16 \%)$. This mainly reflects the tendency for women belonging to recent cohorts to have participation levels higher than those of older cohorts. Moreover, the trend reduction in participation rates due to population ageing is assumed to be offset by the effects of pension reforms.

Unemployment rates are assumed to rapidly converge to their structural level and stay constant thereafter. Unemployment in the euro area is projected to fall from $9.0 \%$ in 2003 to $7.6 \%$ in 2010 and $6.4 \%$ in 2050 . As a result, the reduction in the number of employed people over 2003-2050 is lower than the reduction in the workforce $(5 \%$ versus $8 \%)$.

Labour productivity growth rises from $1.1 \%$ on average over the $2004-10$ period, to $13 / 4 \%$ over the 2011 50 period, thus limiting the slowdown in GDP growth due to falling employment.

\subsection{2 "Expenditure" assumptions}

Given legislation and past contributory careers, pensions are mostly determined by demographic and macroeconomic assumptions, but projections for health and long-term care also depend on other elements such as the evolution over time of: (1) age and gender-contingent demand and consumption of health and long-term care (as summarised in expenditure profiles by age category), and (2) the relative cost of services.

The AWG reference scenario for health expenditure assumes that: (a) half of the projected increase in life expectancy is spent in good health ${ }^{8}$, (b) the income elasticity of health care spending is close to one, and (c) the relative cost of health services does not change over time.

Long-term care projections assume that (a) age-specific disability rates fall by half of the projected decrease in age-specific mortality rates, (b) unit costs increase in line with GDP per worker, and (c) the probability of receiving formal care remains constant. The first assumption implies that about half of the projected gains in life expectancy up to 2050 would be spent in good health and free of disability. The second assumption acknowledges the labour-intensive nature of the sector and, hence, the likelihood of increasing relative costs (different from the reference scenario for health care). The third assumption implies that the share of elderly people receiving formal care remains constant.

\subsection{Risk assessment}

Long-term projection exercises are subject to many uncertainties. These stem from various elements such as macroeconomic or demographic assumptions and the policy implementation risks (e.g. as regards current legislation for pension systems including rules on indexation of pension benefits). We try to identify and assess these risks in the AWG projections and, where they are deemed likely to materialise and quantifiable, we factor them into the projections (see section 1.5). ${ }^{9}$

\subsubsection{Demographic and macroeconomic assumptions}

Changes in life expectancy and old-age dependency ratios may be underestimated. Projections underlying the AWG 2006 exercise were based on the 2000 census. For the countries considered here, a comparison

8 This is an intermediate hypothesis between a "pure ageing" assumption (the age profile of per capita spending on health remains constant over time so that all gains in life expectancy are assumed to be spent in bad health) and a "constant health" assumption (all future gains in life expectancy are spent in good health).

9 We focus the discussion below on the area as a whole. For an overview of the different countries, please refer to the country fiches in the aforementioned Annex. 
with earlier projections based on the 1995 census shows that in the population projections used by the AWG: (a) life expectancy at birth in the base year of the projections is, on average, about one year higher for both men and women; (b) the projected increase in life expectancy at birth up to 2050 is almost one year higher for men; (c) the old-age dependency ratio is 1.5 p.p. higher both at the beginning and at the end of the projection.

Available information suggests that the next update of demographic projections could result in revisions of a similar nature in several countries. Moreover, other demographic assumptions (such as those concerning increases in fertility rates) can be questioned. Longevity projections are surrounded by a significant degree of uncertainty. The degree of this uncertainty is difficult to measure. In the past, the numbers of the elderly (especially the oldest) were systematically under-predicted (Visco, 2006). Yet, this is the group on which much of age-related expenditure is concentrated. There are also significant lags in the production and adoption of mortality tables.

With respect to the macroeconomic assumptions, the projected increase in the participation rate can be considered either as too optimistic or too fast in some countries. Indeed, the overall employment rate is assumed to reach the $70 \%$ Lisbon employment rate target in 2020. Yet, in some countries, improvements made until now do not seem to be in line with this assumption. Finally, concerning the assumed evolution of unemployment one should consider both the variability of NAIRU estimates and the ad-hoc nature of the assumptions regarding the convergence to the EU-15 average.

\subsection{2 "Expenditure" assumptions}

With respect to pension expenditure, risks primarily pertain to the development of entitlements. Specific risks may come from the rising share of the elderly in the voting population, in particular for countries where the replacement ratio is low and/or indexation of pension benefits is lower than nominal wage growth.

Demography and health status are not the only determinants of the evolution of health-care expenditure. Medical practices may change due to technological improvements or to consumer preferences. Moreover, relative costs might increase as productivity growth in the health sector is lower than in the rest of the economy. In the AWG reference scenario, however, all factors different from the evolution of morbidity are taken account of by assuming an elasticity of expenditure to income that is 1.1 at the beginning of the period, gradually declining to 1 thereafter. While the AWG justifies this assumption with OECD data showing that the elasticity has declined in the nineties relative to the eighties (EC 2005), this is likely to be due to the enactment of cost-containment policies (price caps, wage moderation). These policies cannot be sustained forever (Dormont et al, 2007). Assuming a series of repeated cost-cutting reforms would be difficult to reconcile with a no-policy change scenario. The upside risks concerning income elasticity appear larger when considering that it is used as a catch-all term capturing also technological developments. Oliveira Martins and Maisonneuve (2006) show that the growth of health care expenditure per capita has been constantly 1 p.p. higher than that implied by ageing and forecast health status.

Pressure for more public provision/financing of long-term care services could grow in the coming decades due to changes in family structure and women labour market participation. These trends may constrain the supply of informal care within households. For countries with less developed formal care systems today, the projected increase in public spending may underestimate the pressure. ${ }^{10}$

10 This issue is more relevant for the 'southern' Euro-area countries such as Greece, Italy, Portugal and Spain than for Finland, where formal long-term care is already more developed (partly reflecting higher female employment rates). 


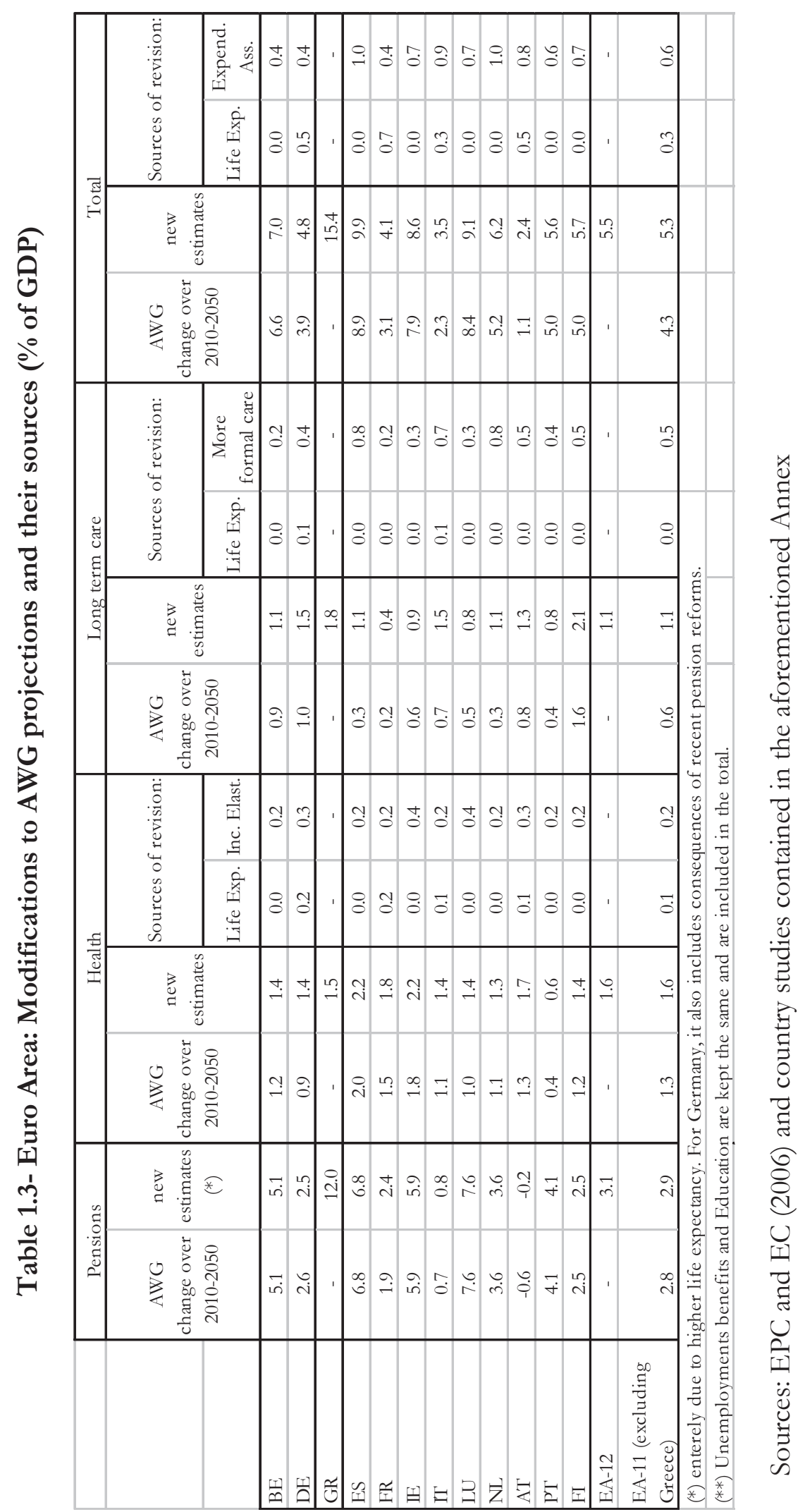




\subsection{Factoring the risks into the projections}

An in-depth risk assessment was carried out for individual euro area member states. ${ }^{11}$ On this basis the AWG reference scenario was modified in a mechanical way taking into account plausible alternative assumptions for key parameters and mostly using information from AWG sensitivity analyses with a view to addressing some of the concerns discussed above.

For countries where more recent demographic projections are available indicating higher life expectancy than in the AWG reference scenario, we increase the expenditure projection by multiplying the difference between those more recent life expectancy estimates and the ones used by the AWG with the impact of an extra life year on spending as estimated by the AWG (an increase in life expectancy at birth of $1-1.5$ year by 2050 is estimated to increase both pension and health expenditure by 0.3 p.p. on average in the EU). ${ }^{12}$

We also use a constant income elasticity of health expenditure as the benchmark assumption (1.1 throughout the projection period). AWG estimates suggest that an increase of 0.1 in the income elasticity of health spending leads to an expenditure increase of 0.6 percent of GDP on average in the euro area.

Finally, our headline scenario is based upon an increase in the provision of formal long-term care. We refer to an AWG simulation based on the assumption of an increase by $1 \%$ a year in the share of dependent elderly people receiving formal care, for the 2004-2020 period, with half the additional people receiving care in institutions and the other half at home: this entails an expenditure increase of 1.1 p.p. of GDP compared to the AWG reference scenario.

\subsection{Conclusions and limitations of our work.}

This different set of assumptions leads to a projected increase in spending of 5.3 p.p. of GDP for the euro area (excluding Greece ${ }^{13}$ ), 1 p.p. more than in the AWG reference scenario (Table 1.3). Higher life expectancy only accounts for 0.3 p.p. of GDP; the effect is especially high for France, Germany and Austria. The increase in formal long-term care leads to 0.5 p.p. of GDP of extra spending, with peaks in Spain, the Netherlands, and Italy. Finally, constant income elasticity of health-care spending inflates projected expenditure by 0.2 p.p. of GDP.

By confining ourselves to alternative AWG scenarios we may still underestimate risks. For instance, a 1.1 income elasticity of health expenditure may still be low; the increase in long-term care may be stronger than what is implied by assuming that per capita spending grows in line with GDP per worker; the shift towards formal long-term care may be more marked than in the AWG scenario.

In addition, we do not take into account policy implementation risks which are especially difficult to quantify as, by their very nature, they reflect entirely discretionary decisions. Such risks may be large. In some countries pensions are indexed to prices only; this will lead to a substantial decline in benefit ratios between the start and the end of the retirement period which may be unsustainable. ${ }^{14}$ There is also a risk that the falling purchasing power of pensions in relation to wage growth will exert pressures on other social security schemes. Pension reforms may thus generate additional costs in the form of income

11 Please refer to the aforementioned Annex.

12 Our use of recent demographic projections is incomplete. New projections do not necessarily revise life expectancy alone. For example, in the case of France, higher fertility rate would partly offset the impact of higher life expectancy on long term expenditure. We could not take this into account as there is no AWG alternative scenario for fertility rates.

13 Including Greece (with alternative sources, documented in the aforementioned Annex) the increase in spending amounts to 5.5 p.p.

14 Knell et al (2006) and the Study Group on Ageing (2007) discuss, respectively, the cases of Austria and of Belgium. 
support and other benefits. Moreover, while projections are based on current legislation, the implementation of provisions to adjust pension spending to demography over time may be delayed. ${ }^{15}$

Finally, we do not factor in macroeconomic risks. The AWG estimates that lower labour productivity growth by 0.25 p.p. over the projection horizon increases the level of pension spending by 0.4 p.p. of GDP on average in the EU. In the euro area changes are the highest in Portugal (1.3 p.p. of GDP) and in Austria and Spain (1.0 p.p.), while in Germany, Ireland, Luxembourg and the Netherlands pensions are connected to earnings and no change is projected due to lower productivity. An employment rate which is 1 p.p. higher than the baseline is projected to result in only small changes (in the 0.0-0.1 range for most countries), unless the increase is concentrated among older workers (an increase by 5 p.p. in the employment rate of older workers is projected to reduce spending by 0.2 p.p. of GDP on average in the euro area, with the highest impacts, 0.3-0.4 p.p., in France, Austria and Belgium).

\section{Ageing and fiscal sustainability}

As indicated in the previous section, ageing will have a substantial impact on the budget balances of almost all euro area countries considered in the 2010-2050 period. In this section, the implications for the sustainability of public finances will be assessed. The first paragraph briefly reviews the theoretical notion of fiscal sustainability and assesses deficit-dynamics in the countries considered. The second paragraph then looks into the quantification of the sustainability gaps for these individual euro area countries.

\subsection{Fiscal sustainability and deficit-debt dynamics}

The notion of fiscal sustainability typically refers to the possibility of continuing current fiscal policy: sustainable policies are those that can be indefinitely continued while unsustainable policies will ultimately have to be modified. However, while the general intuition is clear, different specifications have been provided in the literature ${ }^{16}$, generally pertaining to restrictions on the evolution of public debt.

From a theoretical point of view, notions of sustainability fall into two broad families (Spaventa, 1987). According to Domar (1944), the public debt ratio should converge to a finite value in order to avoid that the tax burden has to rise continuously. Other specifications in the same vein, such as those advocated by Buiter (1985) and Blanchard et al (1990), are more specific and require the debt ratio to converge back to its initial level. These definitions try to capture the idea, first advanced by Keynes (1923) that an everincreasing tax-rate is not sustainable in the long-run.

According to a second, less restrictive notion of sustainability, fiscal policies are sustainable as long as the discounted value of all future primary surpluses equals the current level of public debt (see for example Blanchard et al, 1990). This is in turn true if and only if in the long run the rate of growth of the debt-toGDP ratio is lower than the interest rate ${ }^{17}$. Hence, the 'intertemporal budget constraint' expressed in ratios to GDP is more agnostic with respect to the path of public debt than the other definitions of sustainable policies.

Despite the absence of a clear-cut theoretical benchmark, the 'conventional wisdom' definition of fiscal sustainability would imply that continuously rising and/or extremely high debt ratios are unsustainable.

15 In Italy actuarial updates adjusting entitlements to life expectancy, legislated in 1995 and due in 2005, were postponed. Based on a recent agreement between the government and trade unions, the update is expected to take place in 2010.

16 See Balassone and Franco (2000) for a detailed overview.

17 An infinite number of sequences for the primary balance can in principle satisfy the intertemporal budget constraint and if the latter is expressed in ratios to GDP, some sequences may even imply a continuously increasing debt ratio. 
Against this background, it seems appropriate to first assess the impact of ageing on deficit-debt dynamics in the absence of any policy changes.

To this end, budgetary outcomes for 2050 are calculated here taking into account the macroeconomic projections of the AWG's 2006 Report (European Commission, 2006) and assuming that from 2008 onwards the primary balance is only affected by the ageing-related changes in government expenditure determined in section 1. The implicit interest rate on public debt was assumed to converge to $5.1 \%$ (which corresponds to a real rate of 3\% and inflation of $2 \%$, as assumed by the AWG) for all countries by 2015. No deficit-debt adjustments were taken into account. A similar set of assumptions will be used throughout this section for the calculation of the different sustainability indicators.

\section{Graph 2.1 - Fiscal outcomes in the absence of policy changes ${ }^{1}$}

(percentages of GDP; lightly shaded bars indicate favourable deficit-debt dynamics in the post-2050 period)

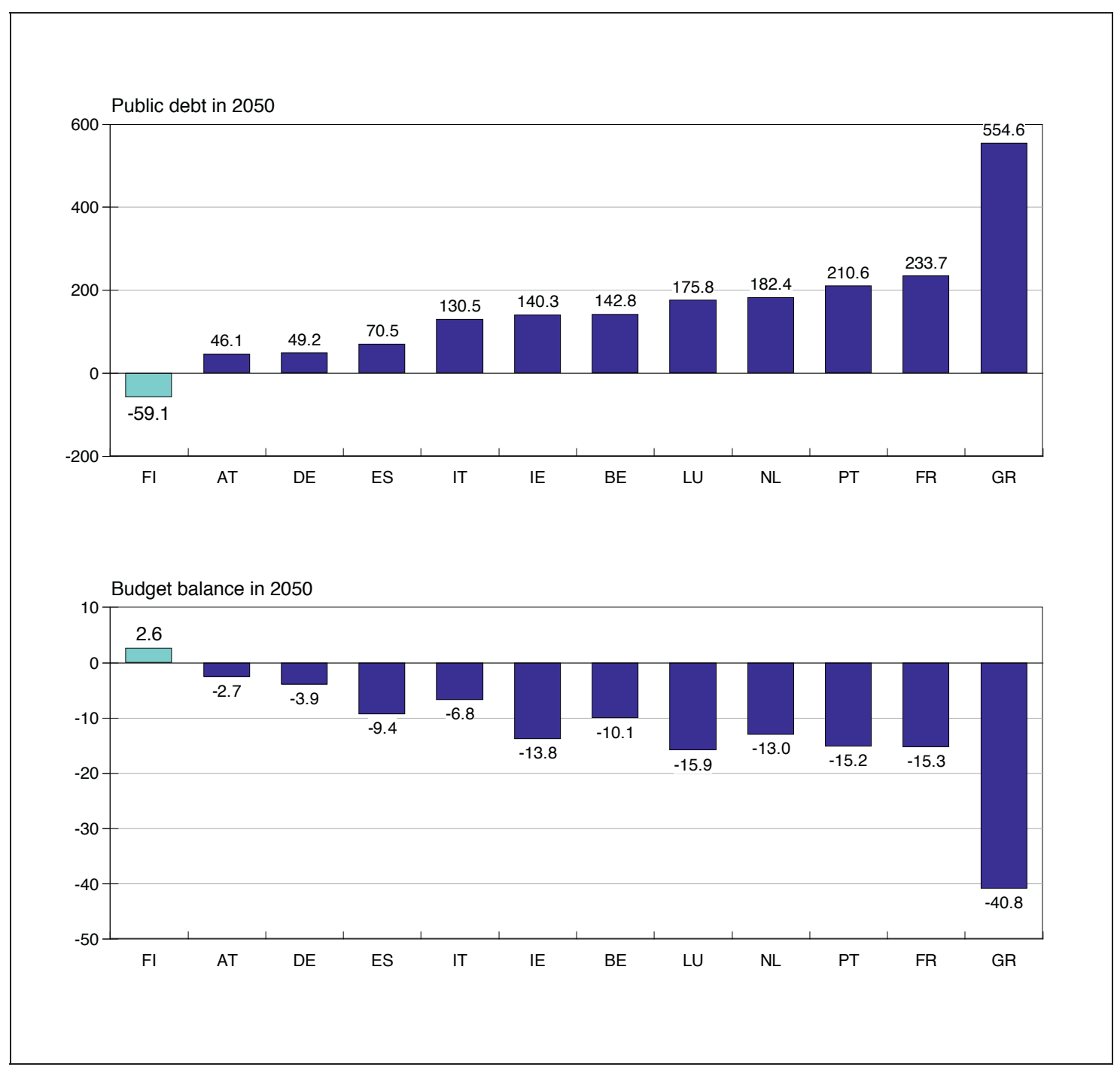

1 Assuming that government revenue and non-ageing related primary expenditure (in structural terms) remain constant with respect to GDP at the 2007 level and that the implicit interest rate on public debt gradually converges to $5.1 \%$ by 2015 .

This exercise suggests that, taking into account the likely budgetary consequences of population ageing in the next decades, public finances are currently only sustainable in Finland. That country would still record a budget surplus of close to $2.5 \%$ of GDP in 2050 with a negative public debt ratio of some $60 \%$ of 
GDP18. Only in Finland deficit-debt dynamics would be favourable at the end of the period considered. All other countries considered would end up with substantial and increasing deficit and debt ratios in 2050 (only in Austria, Germany and Spain public debt would be smaller than GDP in 2050). Hence, it seems clear that in all countries considered, except Finland, policies will ultimately have to be modified.

\subsection{Measurement of sustainability gaps}

As is clear from the wide range of deficit and debt ratios attained in 2050, the extent to which policies have to be changed in order to restore fiscal sustainability differs from country to country. Different approaches for the measurement of these 'sustainability gaps' exist. They typically attempt to quantify the fiscal effort required to reach a certain outcome at a pre-determined date in the future.

In this connection, the tax-gap indicator proposed by Blanchard et al (1990) can be considered as one of the most general examples: it measures the required change in the tax ratio that, taking into account the projected development of primary expenditure and assumptions concerning the implicit interest rate on public debt and deficit-debt adjustments, would yield the same public debt ratio at the end of a given period as the one existing at the beginning of that period. In the context of the ageing problem, the period considered could be the one covered by the projections of ageing-related expenditure pressures (until 2050 in the case of the AWG) and the indicator would then measure the adjustment needed to avoid an increase in the debt ratio due to ageing.

\subsubsection{Sustainability indicators used by the European Commission}

The European Commission typically uses two quantitative indicators in its assessment of the sustainability of public finances in EU Member States (e.g. European Commission, 2007). The so-called S1 indicator is inspired by both the tax-gap indicator proposed by Blanchard et al. and the reference value for public debt defined in the Treaty on the European Community: it is defined as the size of the 'permanent budgetary adjustment necessary for the gross consolidated debt to reach $60 \%$ of GDP in 2050 '. It is more specifically defined as the difference between the primary balance required in a certain target year to bring the debt ratio to $60 \%$ in 2050 - assuming that, after the target year, the primary balance is only affected by the ageing-related expenditure increases - and the one actually projected for that target year. It should be stressed that this S1 indicator is time-dependent. The S1 indicators published by the European Commission are typically linked to a target year in the medium term (e.g. at the end of the time horizon of the stability programmes) but, in principle, $\mathrm{S} 1$ can also be calculated using $\mathrm{t}+1$ as the target year. Apart from the estimates of these ageing costs, the calculation of S1 also depends on a number of assumptions pertaining to activity growth, the implicit-interest rate on public debt and deficit-debt adjustments.

The S1 indicator was re-calculated using 2015 as the target year and taking into account the ageing costs derived in section 1 and using similar assumptions (e.g. on activity growth, the implicit interest rate on public debt, deficit-debt adjustments) as above. For the debt ratio, the gross consolidated debt according to the Maastricht definition was used ${ }^{19}$. The results show that Austria, Germany and, especially, Finland

18 It should be stressed that, in actual practice, a gross consolidated debt ratio (Maastricht definition) can not fall below zero. Negative values for debt ratios used throughout this paper should be understood as a(n increase in the) net financial asset position.

19 For some countries, the European Commission subtracts assets in pension funds from the debt position and therefore uses a modified (net) debt concept (see European Commission, 2005). In theory, i.e. with perfect capital markets, including financial assets as a stock variable in the intertemporal budget constraint leads to the same result as including the return on these assets as a flow variable since, from a present-value perspective, future interest or dividend payments would be equal to the current value of assets. Including both, the stock and the flow variable, however, would imply that the assets are counted twice. As the primary balance includes returns on financial assets, our calculations are based on gross debt figures (i.e. without deducting public pension fund assets).

In addition, we - like the EC (2007) - assume that returns on property income stay constant in relation to GDP which requires a growing asset position. While this might not be fully consistent with the assumption of zero deficit-debt adjustments, the resulting error should be small for most countries. Only for countries with large financial asset positions 
would overshoot the primary balance required by 2015 to reach a 60\% debt ratio in 2050 without any policy changes, as witnessed by the negative values for the S1 indicator. All other countries considered need to tighten fiscal policy in order to prevent the debt ratio from exceeding $60 \%$ in 2050 with the required improvements in the primary balance ranging from $0.2 \%$ of GDP for Spain to $9.4 \%$ of GDP for Greece $^{20}$. These estimates are more pessimistic than those by the European Commission (4/2006), that considers public finances of IE, NL and FI as sustainable according to S1. As pointed out in Langenus (2006) the S1 indicator can be criticised as closing the indicated sustainability gap, i.e. bringing the primary balance to the level suggested by the indicator, only leads to a certain debt ratio by 2050 but does not restrict debt dynamics after that date in any way. For all of the countries considered here, debt dynamics would actually be unfavourable if they implement the fiscal adjustment suggested by the S1 indicator: keeping the primary balance constant after 2050 would imply a (rapidly) increasing debt ratio from the level of $60 \%$ in 2050, which seems at odds with the 'common wisdom' definition of fiscal sustainability. In addition, this clearly violates the Maastricht convergence criterion requiring that debt ratios above $60 \%$ have to be reduced at a satisfactory pace.

\section{Graph 2.2 - Sustainability indicators: $\mathbf{S 1}_{2015}$}

(percentages of GDP)

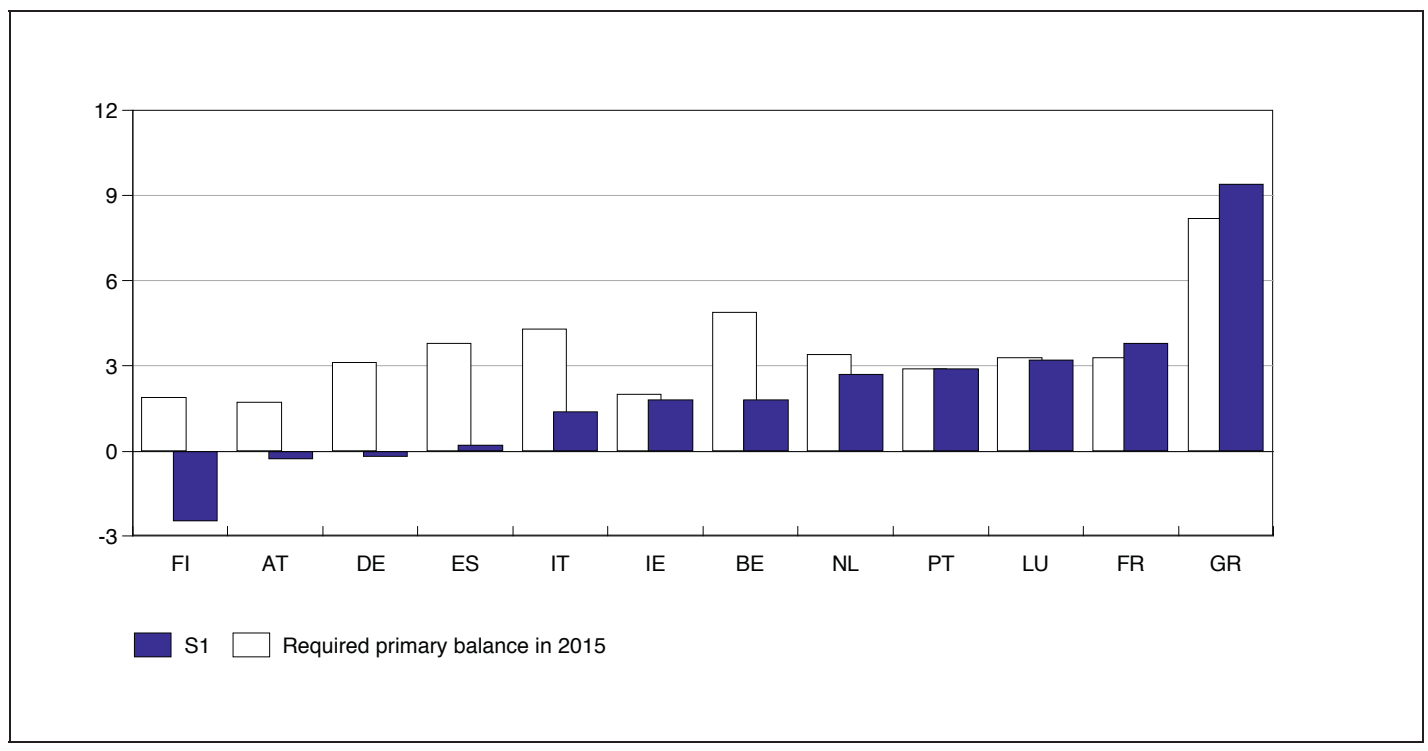

The second sustainability indicator that is routinely used by the European Commission, the so-called S2 indicator, is more directly linked to the aforementioned theoretical definition of sustainability proposed by Blanchard et al (1990): it measures the size of the 'permanent budgetary adjustment necessary to fulfil the intertemporal budget constraint' (European Commission, 2007). It should be stressed that, in principle, an infinite number of sequences for the primary balance can satisfy this constraint. Hence, the indicator needs to be defined more clearly to be operational.

As for S1, the S2 indicator used by the European Commission is time-dependent. The required 'permanent budgetary adjustment' is calibrated as the difference between the primary balance required in a certain target year to equate the present value of the sequence of all future primary balances in percentages of GDP (and assuming that, after the target year, the primary balance is only affected by the ageing-related spending increases) to the debt ratio projected at the beginning of the target year and the

(the Netherlands and Finland) the sustainability indicators might more substantially underestimate the true size of the problem (see European Commission, 2006).

20 As the AWG report (EPC and EC, 2006) does not provide any projections for pension expenditure alternative sources were used, most notably the pension projections in the updates of the Greek stability programme. For further details please see the Greek country fiche in the aforementioned Annex. 
primary balance actually projected for that target year. Under the assumption that growth and interest rates stay constant over time, this can be mathematically expressed as (see European Commission, 2006):

$S 2=\frac{1+r}{1+g}\left(d_{t y-1}-\sum_{i=t y+1}^{\infty} \Delta p b_{i}\left(\frac{1+g}{1+r}\right)^{i-t y}\right)-p b_{t y-1}$

with: $\mathrm{pb}_{\mathrm{i}}=$ (projected) primary balance for year $\mathrm{i}$ (in percentages of GDP)

$\mathrm{d}_{\mathrm{i}}=$ (projected) public debt for year $\mathrm{i}$ (in percentages of GDP)

$\mathrm{r}=$ interest rate

$\mathrm{g}=$ GDP growth rate

ty $=$ chosen target year

It should be stressed that, as S2 (nor S1) is not discounted back to the current year, the exact value of this indicator depends on the chosen target year and will be higher, the further this target year lies in the future.

By choosing the appropriate discount factor - $(1+g) /(1+r)$ in the formula above with, more specifically, $r$ being set equal to the implicit interest rate on public debt - the definition of S2 is clearly linked to the law of motion of the public debt ratio. Since the primary balance is assumed to be affected by the ageing costs only and, hence, stays constant after the last year covered by projections of ageing costs, compliance with the intertemporal budget constraint then implies a constant public debt ratio after that year, as shown in Box 1. As the AWG projections currently cover the years up to 2050, S2 is actually equal to the fiscal effort needed in a given target year to reach a debt-stabilising budget balance in 2050. The corresponding debt ratio reached in 2050 (and maintained thereafter) differs from country to country and depends on the implicit interest rate (which, however, is the same for all countries concerned according to the assumptions used here) and economic growth after 2050 and the primary balance reached in 2050 (see box 1). The latter depends in turn on the initial conditions and the ageing costs.

\section{Box 1 - The intertemporal budget constraint, the S2 indicator and debt dynamics}

The European Commission uses the S2 indicator to operationalise the theoretical benchmark of the intertemporal budget constraint. The purpose of this box is to show that in the particular circumstances studied in this paper (and also assumed by the European Commission to calculate S2) with the activity growth, the implicit interest rate on public debt and the primary balance being assumed constant after a certain date (2050), the S2 indicator is equivalent to imposing a constant public debt ratio from that date onwards.

The intertemporal budget constraint generally implies:

$\mathrm{d}_{0}=\sum_{\mathrm{t}=1}^{\infty} \mathrm{pb}_{\mathrm{i}}\left(\frac{1+\mathrm{g}}{1+\mathrm{r}}\right)^{\mathrm{i}}$

with: $d_{i}=$ debt ratio in year $\mathrm{i}$ 


$$
\begin{aligned}
& \mathrm{pb}_{\mathrm{i}}=\text { the ratio of the primary balance to GDP in year } \mathrm{i} \\
& \mathrm{g}=\text { nominal GDP growth (assumed constant, for simplicity) } \\
& \mathrm{r}=\text { the implicit interest rate on public debt (assumed constant, for simplicity) }
\end{aligned}
$$

if $\forall j\rangle T, p b_{j}=p b_{T}=\overline{p b}$ then (1) reduces to:

$d_{0}=\sum_{i=1}^{T} p b_{i}\left(\frac{1+g}{1+r}\right)^{i}+\left(\frac{1+g}{1+r}\right)^{T} \overline{p b} \sum_{i=1}^{\infty}\left(\frac{1+g}{1+r}\right)^{i}$

Using the formula for the sum of an infinite geometric series, (2) can be rewritten as:

$d_{0}=\sum_{i=1}^{T} p b_{i}\left(\frac{1+g}{1+r}\right)^{i}+\left(\frac{1+g}{1+r}\right)^{T} \overline{p b} \frac{1+g}{r-g}$

which is equivalent to: $d_{0}-\sum_{i=1}^{T} p b_{i}\left(\frac{1+g}{1+r}\right)^{i}=\left(\frac{1+g}{1+r}\right)^{T} \overline{p b} \frac{1+g}{r-g}$

Multiplying both sides of (4) by $\left(\frac{1+r}{1+g}\right)^{T}$ leads to:

$d_{0} \cdot\left(\frac{1+r}{1+g}\right)^{T}-\sum_{i=1}^{T}\left(\frac{1+r}{1+g}\right)^{T-i} p b_{i}=\frac{1+g}{r-g} \overline{p b}$

As the left-hand side of equation (5) is the expression for the debt ratio in T, this implies:

$\overline{p b}=\frac{r-g}{1+g} d_{T} \quad$ (6), which means that: $\forall j>T: d_{j}=d_{t}=\bar{d}$

Hence, the S2 indicator is equivalent to imposing a constant debt ratio in the post-2050 period.

The S2 indicator is also re-calculated here using 2015 as the target year and taking into account the same assumptions as for S1. According to this indicator, public finances are currently only sustainable in Finland. For all other countries the value for S2 is positive, ranging from $0.7 \%$ of GDP in Austria to close to $13 \%$ of GDP for Greece. Similarly, the European Commission (4/2006) only considers public finances sustainable in Finland according to the S2 indicator; however it indicates a much smaller adjustment effort for the remaining countries. The constant debt ratios reached as of 2050, if the fiscal adjustment suggested by the S2 indicator was implemented, also vary greatly, from more than $50 \%$ of GDP in Italy to large negative debt ratios in Spain, Ireland, Luxembourg and Greece. Differences in the stable end-ofperiod debt ratio are mainly related to the primary balance reached at the end of the period by the different countries. In the Italian case, for instance, the primary balance is still positive, which implies a 
positive debt ratio in 2050 (as the implicit interest rate on public debt exceeds nominal GDP growth for all countries). This is also the case for other countries with relatively low ageing costs such as Austria and France. For countries with much higher ageing-related expenditure increases, such as Ireland, Luxembourg, Spain and Greece, the adjustment effort implied by S2 would lead to a primary deficit - and, hence, a negative debt ratio - in 2050.

\section{Graph 2.3 - Sustainability indicators: S2 2015}

(percentages of GDP)

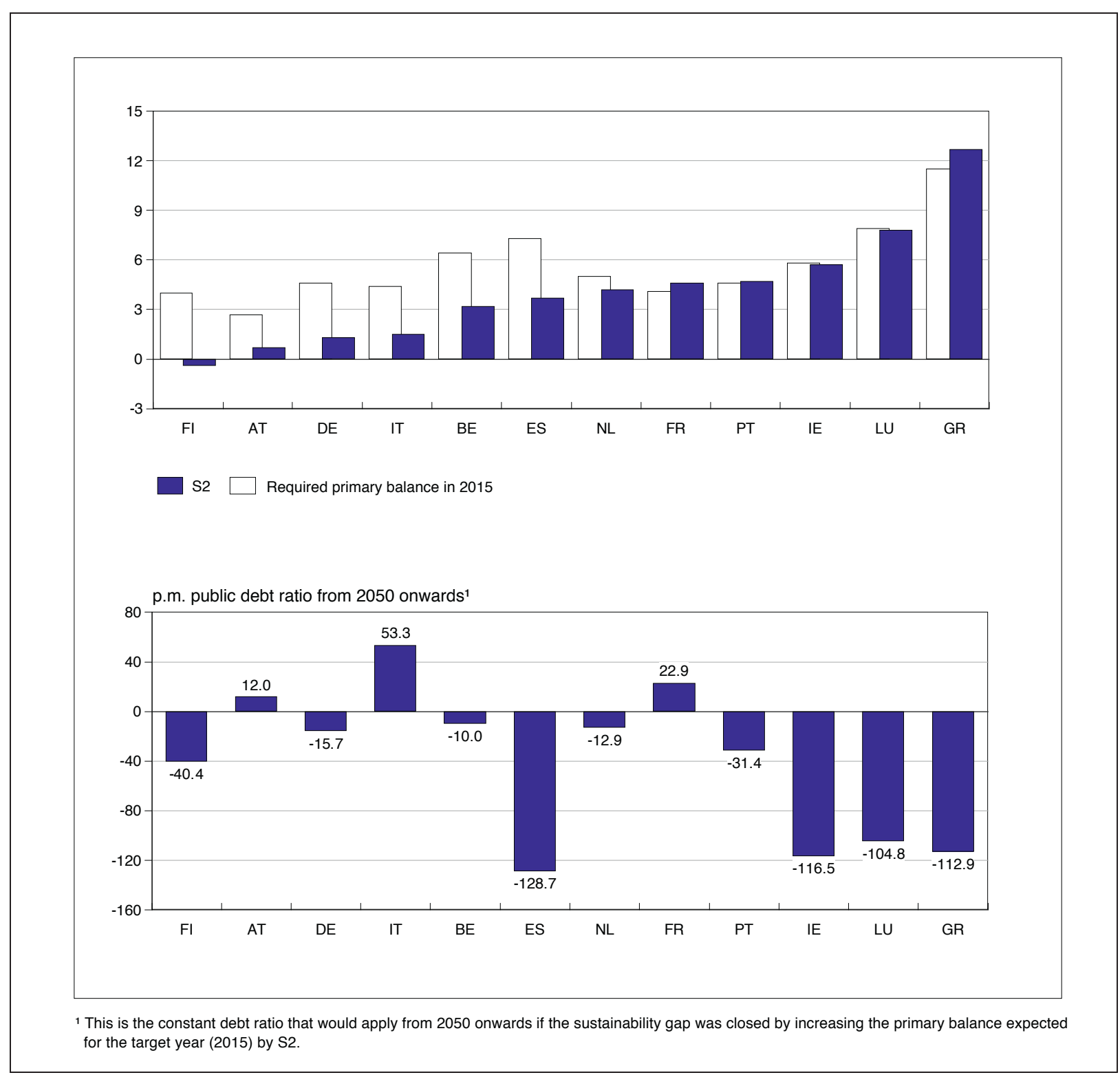

\subsubsection{Alternative sustainability indicators}

Two alternative sustainability indicators are proposed in Langenus (2006). The first one, S3, is a variant of the S2 indicator used by the European Commission. Rather than defining the budgetary adjustment required to reach a debt-stabilising budget balance in 2050 (or, more generally, at the end of the period considered) as an 'abrupt' increase in the target year, the required adjustment is calibrated as a gradual improvement of the primary balance in the years leading up to the target year. As the fiscal adjustment starts earlier, S3 is typically somewhat lower than S2, all other things equal. 
The second alternative indicator, S4 (originally used by Delbecque and Bogaert (1994)) measures the required gradual adjustment in the primary balance in the period up to the target year in order to reach a balanced budget by 2050. Like S1, this indicator does in principle not restrict debt dynamics and may correspond to a rising public debt ratio after the period considered. However, since the restriction imposed by S4 (a balanced budget in 2050) is stronger than the one associated with S1 (a debt ratio of $60 \%$ in 2050), the public finance position at the end of the period considered implied by S4 is typically much sounder than the one implied by S1.

Table 2.1 - Sustainability indicators: S3 2015 and S4 2015 (percentages of GDP)

\begin{tabular}{|c|c|c|c|c|c|c|}
\hline & \multirow[t]{2}{*}{ S3 } & \multicolumn{2}{|c|}{ p.m. } & \multirow[t]{2}{*}{ S4 } & \multicolumn{2}{|c|}{ p.m. } \\
\hline & & $\begin{array}{l}\text { required } \\
\text { primary } \\
\text { balance }\end{array}$ & $\begin{array}{c}2050 \\
\text { debt ratio }\end{array}$ & & $\begin{array}{l}\text { required } \\
\text { primary } \\
\text { balance }\end{array}$ & $\begin{array}{c}2050 \\
\text { debt ratio }\end{array}$ \\
\hline Finland & -0.4 & 4.1 & -38.5 & -0.7 & 3.7 & -19.2 \\
\hline Austria & 0.7 & 2.6 & 10.6 & 0.7 & 2.7 & 5.7 \\
\hline Germany & 1.2 & 4.5 & -18.8 & 1.1 & 4.4 & -10.0 \\
\hline Italy & 1.4 & 4.3 & 48.7 & 1.8 & 4.7 & 25.1 \\
\hline Spain & 3.5 & 7.1 & -139.8 & 2.4 & 6.0 & -75.9 \\
\hline Belgium & 3.1 & 6.3 & -20.1 & 2.9 & 6.1 & -9.7 \\
\hline Netherlands & 4.1 & 4.8 & -26.7 & 3.8 & 4.5 & -12.2 \\
\hline Ireland & 5.5 & 5.6 & -130.5 & 4.1 & 4.3 & -64.4 \\
\hline Portugal & 4.4 & 4.4 & -45.5 & 4.1 & 4.0 & -24.6 \\
\hline France & 4.4 & 3.9 & 7.4 & 4.4 & 4.0 & 3.5 \\
\hline Luxembourg & 7.8 & 7.9 & -130.4 & 5.6 & 5.7 & -43.2 \\
\hline Greece & 12.0 & 10.8 & -151.5 & 10.8 & 9.6 & -80.2 \\
\hline
\end{tabular}

Both of the alternative sustainability indicators were calculated taking into account the same assumptions as for S1 and S2. The results for S3 are very much in line with those for S2: public finances currently only seem to be sustainable in Finland. All other countries will need to adjust their fiscal policy. Sustainability gaps are much smaller in Austria, Germany and Italy than in Ireland, Portugal, France, Luxembourg and, especially, Greece. As for S2, substantial negative public debt ratios are associated with the fiscal adjustment effort implied by S3 in many of the countries considered.

The results for the S4 indicator are quite similar. The ranking of countries on the basis of sustainability concerns is only marginally different: Finland is again the only country where public finances appear to be sustainable while the biggest sustainability gaps are found for the Netherlands, Ireland, Portugal, France, Luxembourg and, especially, Greece. Debt ratios in 2050 associated with the adjustment effort implied by S4 range from $25 \%$ in Italy to large negative values in Greece, Spain and Ireland. For some countries, deficit-debt dynamics at the end of the period considered are unfavourable with the debt ratios set to worsen as of 2050 if the primary balance is kept constant. However, in the sample this is only the case for countries that post negative debt ratios in 2050.

All in all, the analysis carried out in this section clearly shows that population ageing jeopardises fiscal sustainability in all the euro area countries considered except Finland. The actual measurement of sustainability gaps differs depending on the indicators used and, more specifically, their definition of the adjustment effort required to restore sustainability. However, the lowest sustainability gaps are typically 
found for Austria, Germany and Italy - countries that have undertaken more important pension reforms in the recent past - while the problems appear to be more severe in the Netherlands, Ireland, Portugal, France, Luxembourg and, in particular, Greece.

The sustainability indicators used here are based upon a concrete specification of the adjustment effort needed to close the sustainability gap. By their construction, they are typically of the 'pre-funding' type, i.e. they measure the size of an 'early' adjustment effort, as the chosen target year usually does not lie very far in the future. However, this should by no means be interpreted as a policy recommendation: the indicators only measure the size of the problem taking the medium term as the relevant benchmark, they do not imply anything about the appropriateness of such a relatively early adjustment effort to restore fiscal sustainability. The issue of which policy response is more appropriate - e.g. the 'early' fiscal adjustment measured by the sustainability indicators or a more gradual restoration of fiscal sustainability over the whole 2008-2050 period - can only be addressed on the basis of clearly defined criteria and this is done in the next section.

\section{Intergenerational distribution effects of alternative adjustment strategies}

\subsection{Introduction}

So far we have looked at the implications of demographic ageing on the public expenditure of twelve euro area countries on the basis of AWG projections. We have adjusted these estimates where it was deemed appropriate and derived new headline figures for the expected increase in the ratio of ageing-related expenditure to GDP (section 1). On the basis of these new headline estimates sustainability gaps for the twelve countries considered were calculated and it was shown that current policies are not sustainable for most countries (section 2).

In this section, the relative merits of different budgetary strategies to ensure fiscal sustainability are investigated. This question has received considerable attention from EU political bodies for a long time. In a report to the March 2001 European Council of Stockholm, the Commission and the Ecofin Council agreed on a three-pronged strategy for addressing the budgetary consequences of demographic ageing: i) achieving or maintaining budget balances that reduce public debt at a fast pace and thereby lower interest payments and allow for a (partial) pre-funding of ageing-related costs; ii) raising employment rates especially amongst older workers and women, and iii) reforming social transfer systems (possibly including funding of public pensions). More recently, the debate has gained momentum. In the context of the 2005 reform of the Stability and Growth Pact, the Council called for implicit liabilities to be taken into account in the determination of medium-term budgetary objectives (MTOs) for EU member states. In the debate on how to implement this request, one of the main questions is to what extent future ageingrelated expenditure should be pre-funded by attaining high primary surpluses in the following years.

In principle, many different combinations and characteristics of the three-pronged strategy defined in 2001 are conceivable. Here, the focus is exclusively on the budgetary component, i.e. different choices concerning the adjustments to the (primary) budget balance. However, the methodology suggested here can in principle be extended to also include specific reforms aimed at increasing participation rates or reducing ageing-related expenditure. In any case, the impact of past reforms and a gradual increase in participation rates are already included in the adjusted AWG projections which form the basis of this section.

A range of criteria can be applied when assessing the appropriateness of different budgetary strategies. For example, the impact on economic growth could be considered. An early adjustment might require a pronounced fiscal tightening over the following years, which could prove to be disruptive to the economy 
in the short run, even tough it might lead to higher GDP in the long run. ${ }^{21}$ In this paper, we only look at the criterion of intergenerational distribution.

Budgetary strategies can differ with respect to a number of dimensions. We show results that compare strategies affecting different sets of budgetary categories: The case of a lump sum tax is simulated by distributing the adjustment burden equally on persons of all ages while an increase e.g. in social security contributions is modelled by burdening the working age population only. However, the main focus is on strategies that differ with respect to the timing of the adjustment effort. Therefore, an 'early adjustment' scenario, closing the sustainability gap by 2015 , along the lines suggested by the S4 indicator, is compared to a 'gradual adjustment' scenario, in which consolidation is stretched out over the period 2008-2050.

To make sure that the conclusions of the analysis are robust with respect to countries' initial conditions and ageing prospects, a sufficiently diverse group of euro area member states is selected: i) Germany with a low sustainability gap due to a relatively favourable initial budget balance and a slightly below average increase in ageing-related expenditure, ii) Belgium which has a medium-sized sustainability gap, despite a relatively favourable initial budget balance, due to a sharp projected increase in ageing-related expenditure, and iii) France which has a comparatively large sustainability gap, despite a below average expected increase in ageing-related expenditure, due to an unfavourable initial budgetary position. 22

\subsection{Methodology and data}

In the literature, issues of intergenerational distribution are usually analysed within the framework of generational accounting. ${ }^{23}$ Like most sustainability indicators, generational accounting takes into account the intertemporal budget constraint. However, it adds an intergenerational perspective to the analysis. This is achieved by calculating the present value of total net tax payments to the government over the (remaining) lifetime of a cohort born in a specific year, where net tax payments are defined as taxes paid minus transfers received. ${ }^{24}$ This present value of net tax payments is labelled generational account. The intergenerational distribution of the net tax burden is analysed by comparing the generational accounts of different cohorts. ${ }^{25}$

Usually, the generational account of a newborn in the base year is compared to that of future generations (those born after the base year). According to the customary, albeit arbitrary, convention in generational accounting, all generations already living in the base year are exempted from the policy change necessary to satisfy the intertemporal budget constraint while any required adjustment effort is spread evenly over all future generations. Therefore, generational accounts in general indicate a higher burden for future generations if a sustainability gap exists.

21 See e.g. Hauner, Leigh and Skaarup (2007).

22 This assessment is based on the results for the S4 indicator shown in table 2.1. The European Commission (2008) judges the three considered countries to be at "medium risk" with Germany being a borderline case to low risk.

23 A different approach has been suggested by Langenus and Eugène (2005) and applied by Langenus (2006). They compare the implications of different budgetary strategies on the evolution of an average working-age person's financial contribution to the government's primary balance over time. They regard a situation in which successive generations of workers contribute roughly the same amount, corrected for nominal wage growth, as "intergenerationally fair". The main difference between this and the generational accounting approach is that they take a cross-section instead of a longitudinal perspective, as they focus on net tax payments for individual years rather than over the total lifetime of a cohort.

24 In some studies, not only transfers but also other government expenditure such as spending on general administration, domestic and external security, and investment are allocated (evenly) to different cohorts.

25 Of course, only generational accounts at birth are comparable as the generational account of e.g. a 30-year old person fails to reflect the net tax payments already borne over the first three decades of his/her life. For a more detailed description of the generational accounting approach see, for example, Auerbach, Gokhale and Kotlikoff (1994), Raffelhüschen (1999) or Bonin (2001). 
In this section, we in principle follow the generational accounting approach. However, the conventional generational accounting methodology has several drawbacks with regard to our objective and we tried to accommodate this by introducing some modifications. Firstly, most generational accounting studies for Europe forecast pension expenditure on the basis of their own models. These models are necessarily less elaborate than the sometimes very sophisticated pension models and databases that are used in projections by national institutions. Since future pension expenditure is determined not only by cohort effects but also by numerous legislative changes the full impact of which is sometimes only felt after several decades, it is preferable to revert to pension forecasts made with large models and a comprehensive database. This might be less obvious for other revenue and expenditure categories which are less influenced by effects that fully mature only after a long time. By basing our calculations on the (adjusted) AWG projections, we benefited from the detailed national forecasts that enter these projections. ${ }^{26}$ This approach also ensures consistency - except for the adjustments made in section 1 with the AWG projections which underlie the sustainability analysis at the European level. However, this procedure also implies that all revenue and expenditure categories not deemed to be age-specific by the AWG are distributed evenly over all cohorts - an assumption that is clearly not in line with empirical facts. However, with a more extensive database, this exercise could be extended to a fully-fledged generational accounting procedure with age-specific expenditure profiles for a wide range of additional budgetary categories.

A second drawback of the standard generational accounting approach is that the focus is on two cohorts only - newborns and those born one year later (representing future generations). As shown, for example, by Bonin (2001), with increasing life expectancy and policy measures that become effective only in the future, generational accounts of future generations cannot just be represented by the cohort born immediately after the base year: the generational account changes for every future generation. Moreover, considering the full lifetime generational accounts only of cohorts born in the base year (2007 in our study) or later implies that the intergenerational redistribution between all currently living cohorts can not be analysed correctly. We therefore explicitly calculate total lifetime generational accounts for the cohorts born between 1970 and $2050 .{ }^{27}$ To our knowledge, this has rarely been done before. ${ }^{28}$

We then compare lifetime generational accounts under different budgetary strategies. Instead of explicitly targeting an 'optimal' strategy that minimises intergenerational redistribution, we compare two strategies that differ in the timing of the adjustment. In the first strategy, named early adjustment approach, the primary balance is increased in equal yearly steps until 2015 to ensure a balanced budget in 2050. In the second strategy, named gradual approach, the fiscal adjustment is spread out over the whole 2008-2050 period. This gradual adjustment is calibrated to generate the same public debt ratio in 2150 as the early adjustment strategy with a view to making both strategies comparable when analysing their intergenerational implications.

The restriction of an identical public debt ratio in 2150 may not be fully satisfactory when comparing the lifetime burden for two alternative budgetary strategies of generations born until 2050 only as the public debt ratio in 2150 is obviously also affected by (part of) the lifetime burden of generations born in the 2051-2150 period. Theoretically, a comparison of alternative budgetary strategies on the basis of intergenerational equity may then be biased by neglecting the generations born after 2050. However, alternative restrictions to make the budgetary strategies considered comparable - e.g. an identical debt ratio in 2050 - were deemed to be less appropriate. 'black box' to outsiders. The AWG tries to overcome this problem by a peer review process.

27 While more generations are alive in the period 1970 to 2150 in which we analyse public finance developments, only for cohorts born between 1970 and 2050 their whole lifespan is covered. 
Once the calculations are done, we need a criterion to decide which strategy has the more equitable distributional consequences. In the literature, several alternatives are proposed. Among the most prominent are the utilitarian social welfare function, that under restrictive assumptions implies redistribution until complete equality is achieved, and the maximin criterion proposed by Rawls, which maximises the utility of the person with the minimum utility. ${ }^{29}$ However, the assumptions under which these results are derived are highly questionable and it is unclear how this should be applied in an intertemporal setting. In this regard, taking a constant net tax burden across different generations as a benchmark is an appealing solution. It is an economical solution in terms of computational effort, it is easily understood and has the property to give equal weight to present and future generations even though the latter do not take part in current political decision-making process. It needs to be pointed out, however, that the intergenerational distribution of the burden imposed by government budgetary activity is ultimately a normative question that does not have clear-cut answers. ${ }^{30}$ An efficiency argument may also be made for an even distribution of lifetime net tax payments, as Barro (1979) has shown that an unchanged tax ratio minimises the deadweight loss of taxation. ${ }^{31}$

Therefore, in this paper an adjustment strategy will be deemed preferable if it leads to a flatter time profile for the total net tax burden across cohorts born in different years. This assumes that a relatively constant net lifetime contribution to the government's primary balance (deflated by nominal per capita GDP) across generations can be deemed equitable. This is methodologically close to imposing a constant lifetime net tax rate for all generations - a concept named generational balance in the generational accounting literature. Alternative definitions could pertain to keeping either the absolute (discounted) amount of the lifetime contribution constant across generations or the difference between market income and this amount constant across generations. These definitions would be consistent with a net tax rate that is, respectively, constantly decreasing or increasing over time.

The lifetime generational account of an average person born in year $k$ is given by

$$
G K_{k}=\sum_{s=k}^{k+D} \sum_{z} h_{s-k, z, s} S_{s, k} \frac{1}{(1+r)^{s-k}} .
$$

In this equation, $D$ represents the highest age considered, $h_{a, z, s}$ the age-specific per capita amounts of individual revenue and primary expenditure categories $\mathrm{z}$ for a person of age $a$ in year $s$ and $S_{s, k}$ the likelihood of a person born in $k$ to survive until period $s$, while $r$ denotes the discount rate.

The age-profiles $h$ for the individual ageing-related expenditure categories (pension, health, long-term care, unemployment and education) are taken from various sources. ${ }^{32}$ However, the delineation of these sources often does not exactly match those in the national accounts. It is therefore clear that the payment profiles obtained in this way and extrapolated to cover the population as a whole deviate from the aggregate figures shown in the national accounts. For this reason we adopt a two-stage approach, as is customary in the literature. In the first stage, the age-specific payment profiles are derived from the various data sources. In the second stage, the age-specific per capita amounts are multiplied by a scaling factor which is uniform for all age groups. This scaling factor is defined so as to ensure that in the aggregate - taking into account the size of the age classes - the respective national account figure is reached. In other words, while in the first stage only the relative positions of persons of different ages are determined, in the second stage the absolute payment profiles are calculated.

\footnotetext{
29 See e.g. Rosen (1999) and Rawls (1971).
}

30 In fact, similar to progressive income taxation, an intertemporally rising net tax rate has sometimes been proposed in the literature in order to redistribute from (richer) future to (poorer) currently living generations.

31 However, Barro's proposition only holds under certain assumptions and moreover relates to the (marginal) tax rate while here we refer to net taxes (taxes minus transfers).

32 As pointed out above, all other budget categories are distributed evenly over all age classes. 
This two-stage approach not only ensures consistency between absolute age-specific payment profiles and the national accounts data but also allows us to circumvent the limitation that we usually have relative payment profiles only for one point in time. Since the relative payment profiles typically change little over time, it is possible to use relative payment profiles which were obtained before (or after) the year under consideration, without this involving a major error. ${ }^{33}$ By contrast, the national accounts data needed for calculating the absolute payment profiles (which are subject to stronger fluctuations) are available for all years in the period from 1970 to 2050.

The national accounts figures for the years from 1970 to 2007 for the five age-related expenditure items, the (primary) balance and GDP are available from national statistical institutes. However, the delineation often differs from that used by the AWG. Therefore a scaling factor was used in order to align national accounts figures to the AWG definition. ${ }^{34}$ For the period 2008 to 2050 we used the adjusted AWG projections derived in section 1 . For the years 2050 to 2150 we held the absolute age-profiles we obtained for 2050 constant (except for an adjustment for inflation and per capita GDP growth) and computed the macroeconomic aggregates by combining these profiles with the population forecast.

The population data are likewise taken from national sources for past years while AWG figures were used for the years up to 2050.35 After 2050 the population is held constant in the baseline. However, keeping not only overall population size but also population structure at the 2050 level is clearly not realistic for most countries. This is why in a sensitivity analysis we also calculated national accounts on the basis of an explicit population projection that applies the AWG's fertility, mortality and migration assumptions for 2050 to the following years as well.

Concerning the discount rate employed for deriving the present value of lifetime net tax payments, we relied on the AWG's assumption of a real interest rate of $3 \%$ and inflation of $2 \%$ for future years. For the past we used the yield on long-term bonds issued by the respective government. The absolute payment profiles for the years after 2050 were extrapolated with the growth rate of GDP per capita, while GDP was expected to continue to grow with the rate assumed by the AWG for the period 2040 to 2050. The latter assumption reflects the method chosen by the Commission, and adopted also in section 2 of this paper, for the calculation of sustainability indicators. In order to make lifetime net tax payments of different cohorts comparable, they were discounted by the nominal growth rate of per capita GDP. While other methods are conceivable, this implies that the lifetime net tax payment is adjusted for increases in GDP per capita for successive cohorts. So when cohorts are shown to have the same lifetime net tax payments this does not imply that their absolute net tax payments are equal, but that their lifetime net payments in relation to per capita GDP at birth are similar.

Obviously, all the methodological and data limitations that fully-fledged generational accounting exercises are subject to also apply to our more restricted approach. ${ }^{36}$ Moreover, since we follow the AWG's presumption that most revenue and expenditure categories are not age-specific, while in fact generational accounting studies have shown a clear lifecycle pattern for them, the absolute value of our lifetime net tax payments should be interpreted with great caution. The same holds for the differences in the total lifetime burden between countries as well as between males and females. The latter depend on a sometimes

33 While most policy measures leave the relative age-specific payments profiles unaffected, these profiles change, for example in the case of a legislated increase in the retirement age.

34 The scaling factor reflects the difference between national accounts and AWG data for 2004. In the case of Germany, a similar procedure was applied to link east German to west German data for the years before reunification. In addition for Germany some budgetary items like e.g. development aid were assumed not to benefit or burden the resident population. Also therefore results are not fully comparable between countries.

35 Survival probabilities for past years were obtained from the Human Mortality Database, University of California, Berkeley (USA), and Max Planck Institute for Demographic Research (Germany). Available at http://www.mortality.org or http://www.humanmortality.de. As pointed out in section 1, the data from the AWG relate to the reference scenario and are not fully compatible with the adjusted headline scenario.

36 See Havemann (1994), Raffelhüschen (1999), or Manzke (2002). 
arbitrary allocation of payments within households. This is why we chose to show either the lifetime net tax payments for women or for men for a specific country. The comparison between the lifetime net tax payments of different cohorts is, however, more meaningful. Nevertheless, our results should be treated with some caution when drawing policy conclusions. While the basic methodological framework we use is, in our view, adequate for analysing intergenerational distribution issues, we were confronted with considerable deficiencies on the data side. Our results should therefore be taken as an indication for what would be possible with a more complete data set.

\subsection{Results: Comparing the lifetime net tax burden of alternative adjustment strategies for different cohorts}

\subsubsection{Results for the baseline}

In the baseline scenario we compare the intergenerational distribution of lifetime net tax payments of different cohorts under the assumption that the required adjustment is accomplished by increasing the primary budget balance through any of the non-ageing related categories. This implies that the adjustment burden is distributed evenly over all age classes. The picture that emerges in this case is quite similar for the three countries considered (compare graphs 3.1 to 3.3). Earlier-born cohorts who have already entered into working age face the lowest burden, while later-born generations have to pay much higher net taxes. The burden increase is very steep between the 1980 cohort and the 2005 cohort (1970 and 1995 for Belgium). For subsequent cohorts, the burden declines slightly under the early adjustment strategy, while it keeps increasing - though less rapidly than between the 1980 and 2005 cohorts - under the gradual adjustment strategy (with the exception of Germany, where the burden declines after the 2005 cohort also under the gradual adjustment strategy). As could be expected, the lines for the early adjustment and the gradual strategy are quite close together in the case of Germany, which has a small sustainability gap, and are wider apart for the other two countries, where larger adjustment efforts are needed. In fact, if sustainability had already been attained and no further adjustments were required, the lines would match exactly. None of the strategies considered would, however, sufficiently burden currently living generations and alleviate future generations to achieve an even intergenerational distribution. ${ }^{37}$

Visual inspection of graphs 3.1 to 3.3 already reveals that the early adjustment strategy leads to more even outcomes than the gradual one. In all three countries considered, it levies a higher burden on earlier-born cohorts who, compared to later-born cohorts, face a lower burden and relieves cohorts born later that face higher net tax payments than older cohorts. The crossing of the two lines, which indicates a lower burden under early adjustment for all later-born cohorts, is reached around the year 2016, while the highest burden under early adjustment is borne by the cohorts born about a decade earlier. For France and Belgium, the burden for generations born close to the middle of the $21^{\text {st }}$ century obtained under the gradual approach would be markedly higher than the peak burden for generations born around 2005 under early adjustment. For Germany, the peak is attained around 2005 under both strategies and is slightly higher under early adjustment.

37 A higher burden on currently living generations could be attained by concentrating the adjustment effort on the elderly. However, as pointed out earlier, searching for budgetary strategies that lead to an even intergenerational distribution is not the objective of this paper. 


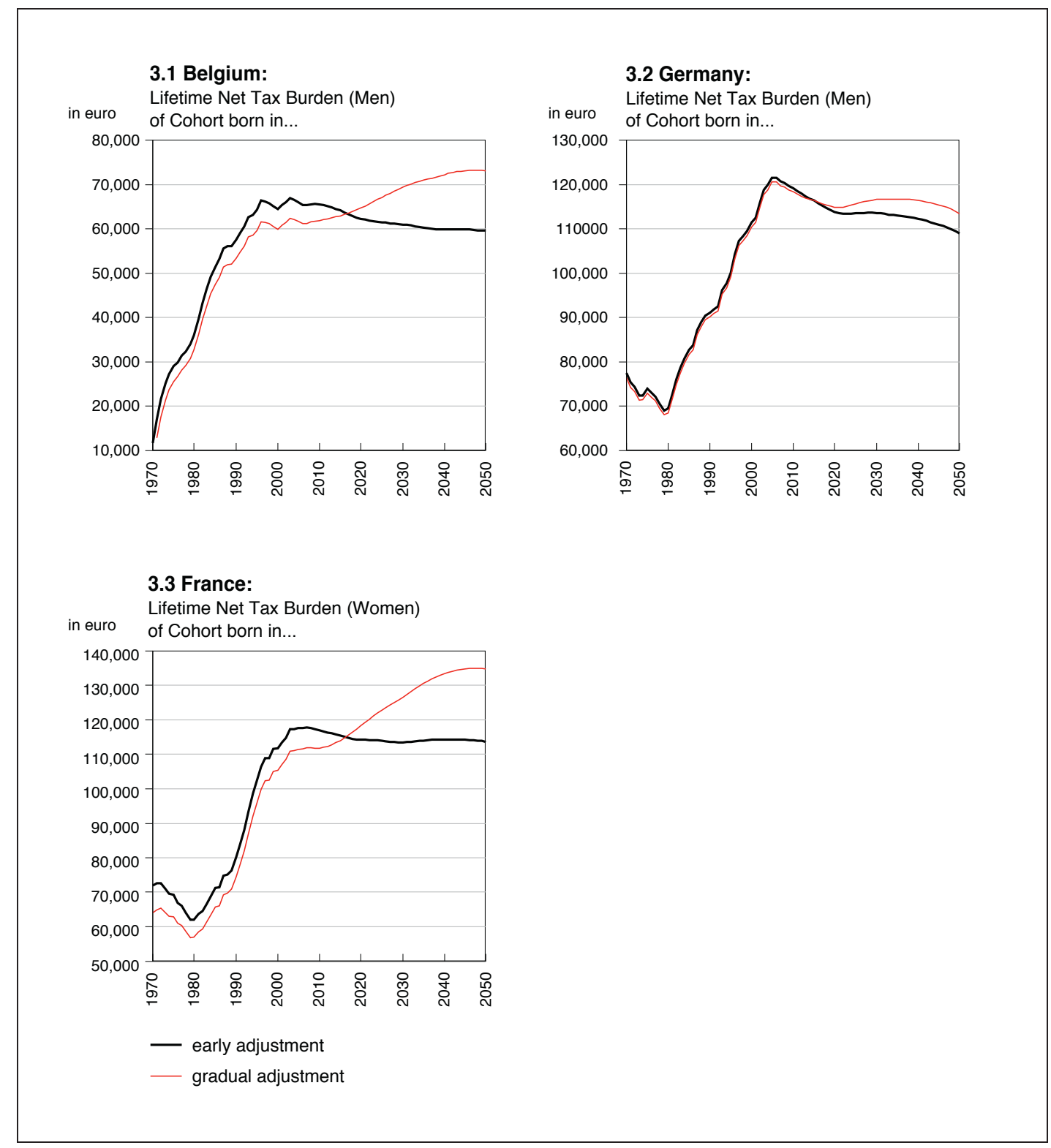

The conclusion that the early adjustment strategy leads to a more even intergenerational distribution is confirmed by the range of indicators displayed in table 3.1. The maximum burden, the difference between the maximum and the minimum burden and the standard deviation all point to a more favourable outcome under early adjustment. As already apparent from the graphs, the maximum burden for Germany is the only exception while the difference between the maximum and the minimum burden is about the same for that country. Nevertheless, as shown in table 3.1, even for Germany the standard deviation (and the coefficient of variation) is lower in the case of early adjustment. ${ }^{38}$

38 Indeed, at least for our sample of countries, the intergenerational distribution of the early adjustment strategy seems to be the more even compared to the gradual adjustment strategy the larger the initial sustainability gap. 
Table 3.1: Intergenerational distribution indicators (baseline scenario)

\begin{tabular}{|c|c|c|c|c|c|c|c|c|}
\hline & \multicolumn{2}{|c|}{$\begin{array}{l}\text { Maximum burden minus } \\
\text { minimum burden* }\end{array}$} & \multicolumn{2}{|c|}{ Standard deviation* } & \multicolumn{2}{|c|}{ Coefficient of variation } & \multicolumn{2}{|c|}{ Maximum Burden* } \\
\hline & $\begin{array}{c}\text { Early } \\
\text { Adjustment }\end{array}$ & $\begin{array}{c}\text { Gradual } \\
\text { Adjustment }\end{array}$ & $\begin{array}{c}\text { Early } \\
\text { Adjustment }\end{array}$ & $\begin{array}{c}\text { Gradual } \\
\text { Adjustment }\end{array}$ & $\begin{array}{c}\text { Early } \\
\text { Adjustment }\end{array}$ & $\begin{array}{c}\text { Gradual } \\
\text { Adjustment }\end{array}$ & $\begin{array}{c}\text { Early } \\
\text { Adjustment }\end{array}$ & $\begin{array}{c}\text { Gradual } \\
\text { Adjustment }\end{array}$ \\
\hline $\begin{array}{l}\text { Belgium } \\
\text { Women } \\
\text { Men } \\
\end{array}$ & $\begin{array}{l}58,200 \\
55,200 \\
\end{array}$ & $\begin{array}{l}65,100 \\
65,800 \\
\end{array}$ & $\begin{array}{l}12,800 \\
12,900 \\
\end{array}$ & $\begin{array}{l}15,600 \\
16,100 \\
\end{array}$ & $\begin{array}{l}20.4 \\
23.0 \\
\end{array}$ & $\begin{array}{l}24.1 \\
27.9 \\
\end{array}$ & $\begin{array}{l}76,000 \\
66,900 \\
\end{array}$ & $\begin{array}{l}78,800 \\
73,300 \\
\end{array}$ \\
\hline $\begin{array}{l}\text { Germany } \\
\text { Women } \\
\text { Men }\end{array}$ & $\begin{array}{l}56,300 \\
52,500 \\
\end{array}$ & $\begin{array}{l}56,300 \\
52,500 \\
\end{array}$ & $\begin{array}{l}29,600 \\
26,500 \\
\end{array}$ & $\begin{array}{l}30,400 \\
27,400 \\
\end{array}$ & $\begin{array}{l}25.7 \\
26.7 \\
\end{array}$ & $\begin{array}{l}26.2 \\
27.3 \\
\end{array}$ & $\begin{array}{l}140,400 \\
121,600 \\
\end{array}$ & $\begin{array}{l}139,600 \\
120,500 \\
\end{array}$ \\
\hline $\begin{array}{l}\text { France } \\
\text { Women } \\
\text { Men } \\
\end{array}$ & $\begin{array}{l}55,800 \\
49,400 \\
\end{array}$ & $\begin{array}{l}78,100 \\
72,600 \\
\end{array}$ & $\begin{array}{l}19,900 \\
18,500 \\
\end{array}$ & $\begin{array}{l}27,000 \\
25,600 \\
\end{array}$ & $\begin{array}{l}19.7 \\
23.9 \\
\end{array}$ & $\begin{array}{l}25.9 \\
32.3 \\
\end{array}$ & $\begin{array}{c}117,700 \\
92,300 \\
\end{array}$ & $\begin{array}{l}134,900 \\
109,400 \\
\end{array}$ \\
\hline
\end{tabular}

* In euros, deflated by per capita GDP growth

\subsubsection{Sensitivity Analysis}

In order to test the robustness of our results, we performed several sensitivity analyses. First, we tested the impact of an alternative assumption on the distribution of the adjustment burden over the different age groups. In fact, it seems quite reasonable to expect that the adjustment burden will not be spread out evenly over all age-classes but will be concentrated on the population of working-age. Indeed, it is a well established outcome of fully-fledged generational accounting studies that the working-age population bears the highest net tax burden. We therefore ran a scenario with the adjustment burden only on persons between 20 and 59 years old. The outcome can be taken as an indication of the intergenerational burden distribution when sustainability is achieved e.g. by increasing social security contributions. Graphs 3.4 to 3.6 show that the date after which newborns would prefer the early adjustment to the gradual strategy falls about a decade earlier for all three countries. Moreover, the difference between the two strategies increases for earlier-born cohorts. Nevertheless, the intergenerational distribution indicators depicted in table 3.2 indicate that the basic conclusion that early adjustment entails a more even distribution continues to hold. Indeed, all indicators except for the maximum burden for Belgium and Germany support this finding.

Table 3.2: Intergenerational distribution indicators (adjustment burden on persons aged 20-59)

\begin{tabular}{|l|c|c|c|c|c|c|c|c|}
\hline & \multicolumn{2}{|c|}{$\begin{array}{c}\text { Maximum burden minus } \\
\text { minimum burden* }\end{array}$} & \multicolumn{2}{|c|}{ Standard deviation* } & \multicolumn{2}{c|}{ Coefficient of variation } & \multicolumn{2}{c|}{ Maximum Burden* $^{*}$} \\
\cline { 2 - 9 } & $\begin{array}{c}\text { Early } \\
\text { Adjustment }\end{array}$ & $\begin{array}{c}\text { Gradual } \\
\text { Adjustment }\end{array}$ & $\begin{array}{c}\text { Early } \\
\text { Adjustment }\end{array}$ & $\begin{array}{c}\text { Gradual } \\
\text { Adjustment }\end{array}$ & $\begin{array}{c}\text { Early } \\
\text { Adjustment }\end{array}$ & $\begin{array}{c}\text { Gradual } \\
\text { Adjustment }\end{array}$ & $\begin{array}{c}\text { Early } \\
\text { Adjustment }\end{array}$ & $\begin{array}{c}\text { Gradual } \\
\text { Adjustment }\end{array}$ \\
\hline $\begin{array}{c}\text { Belgium } \\
\text { Women }\end{array}$ & 69,500 & 71,800 & 14,300 & 18,400 & 21.8 & 26.9 & 87,400 & 80,800 \\
Men & 66,000 & 70,600 & 13,800 & 18,800 & 23.2 & 29.9 & 78,800 & 74,900 \\
\hline Germany & & & & & & & & \\
Women & 58,000 & 60,900 & 30,100 & 31,400 & 25.6 & 26.6 & 144,300 & 143,700 \\
Men & 54,300 & 57,100 & 27,000 & 28,400 & 26.5 & 27.8 & 125,600 & 125,000 \\
\hline France & & & & & & & & \\
Women & 59,900 & 82,600 & 18,600 & 31,400 & 17.5 & 28.6 & 127,700 & 135,800 \\
Men & 55,900 & 82,300 & 17,200 & 29,900 & 20.4 & 34.1 & 102,700 & 112,500 \\
\hline
\end{tabular}

* In euros, deflated by per capita GDP growth 




We also tested the robustness of our results with respect to the assumption of constant population size and structure after 2050. This assumption is clearly unrealistic. It would involve not only a sudden jump in fertility rates but also high migration for some age groups. As it turns out, explicitly forecasting the population after 2050 actually reinforces our conclusions (see graphs 3.7 and 3.8 as well as table 3.3). For Germany, when the mortality, fertility and migration rates projected by the AWG for 2050 are also applied to the following years, ${ }^{39}$ the early adjustment strategy is preferred according to all intergenerational distribution indicators. The true burden of the cohorts born between 1980 and 2040 is overestimated in the constant population scenario. For France, the changes are less pronounced but go in the same direction. 40

39 With the population forecast the overall population falls to 58.0 million and the dependency ratio to $51.8 \%$ by 2100 compared to 75.4 million and $53.1 \%$ with a constant population.

40 We did not run this exercise for Belgium. 
Table 3.3: Intergenerational distribution indicators (with population forecast for years after 2050)

\begin{tabular}{|l|c|c|c|c|c|c|c|c|}
\hline & \multicolumn{2}{|c|}{$\begin{array}{c}\text { Maximum burden minus } \\
\text { minimum burden* }\end{array}$} & \multicolumn{2}{|c|}{ Standard deviation* } & \multicolumn{2}{c|}{ Coefficient of variation } & \multicolumn{2}{c|}{ Maximum Burden* } \\
\cline { 2 - 8 } & $\begin{array}{c}\text { Early } \\
\text { Adjustment }\end{array}$ & $\begin{array}{c}\text { Gradual } \\
\text { Adjustment }\end{array}$ & $\begin{array}{c}\text { Early } \\
\text { Adjustment }\end{array}$ & $\begin{array}{c}\text { Gradual } \\
\text { Adjustment }\end{array}$ & $\begin{array}{c}\text { Early } \\
\text { Adjustment }\end{array}$ & $\begin{array}{c}\text { Gradual } \\
\text { Adjustment }\end{array}$ & $\begin{array}{c}\text { Early } \\
\text { Adjustment }\end{array}$ & $\begin{array}{c}\text { Gradual } \\
\text { Adjustment }\end{array}$ \\
\hline Germany & & & & & & & & \\
Women & 53,100 & 59,500 & 30,400 & 32,100 & 25.9 & 27.3 & 137,800 & 140,700 \\
Men & 47,000 & 52,200 & 25,800 & 27,500 & 26.2 & 27.7 & 117,100 \\
\hline France & 52,700 & 78,100 & 18,800 & 26,300 & 19.1 & 25.9 & 113,900 & 134,300 \\
Women & 44,800 & 68,400 & 16,300 & 23,700 & 22.3 & 31.4 & 87,200 & 105,000 \\
\hline
\end{tabular}

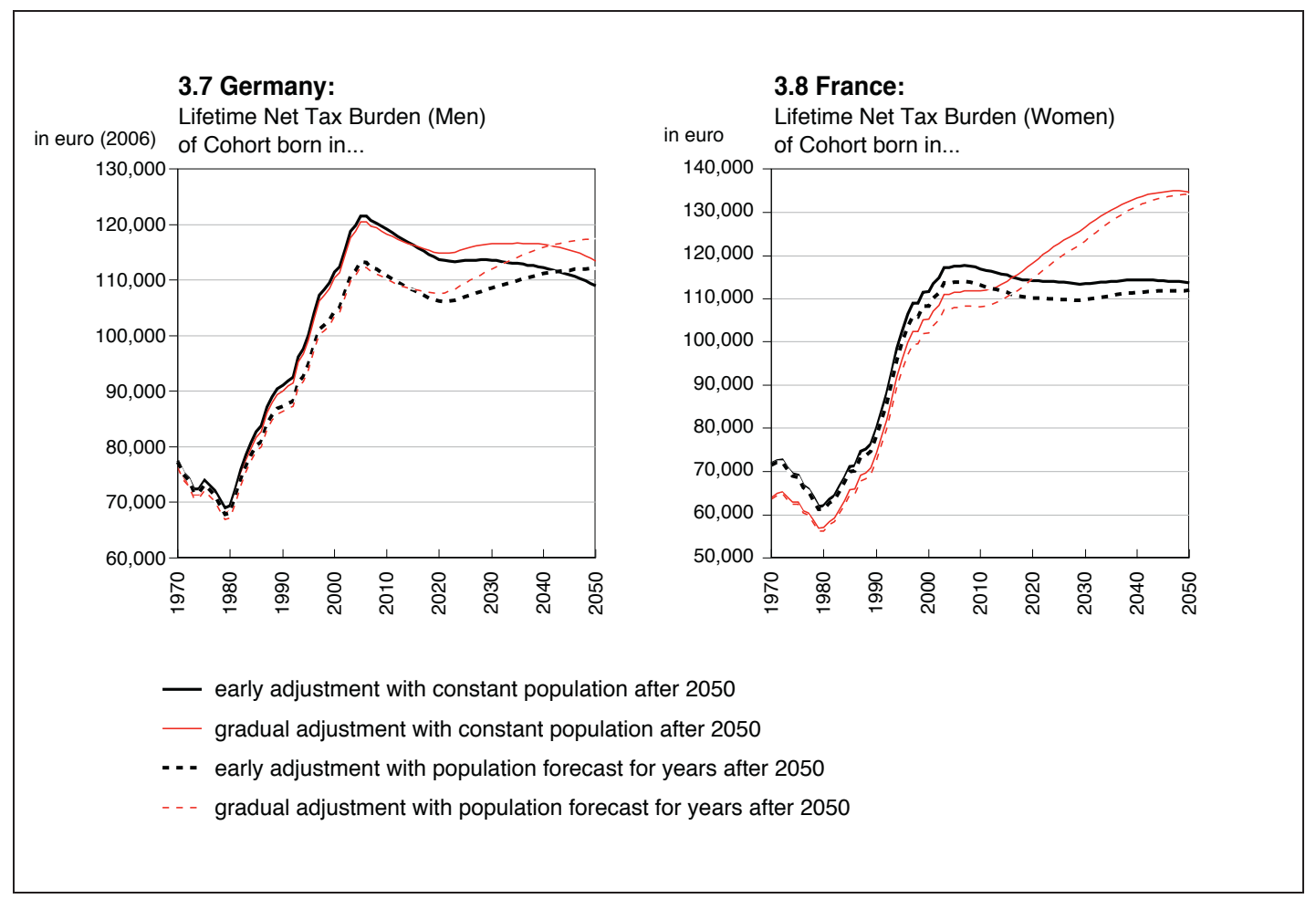

As a third sensitivity test, instead of making net tax burdens of different cohorts comparable by adjusting for the increase in GDP per capita between the respective birth years, lifetime net tax rates can be calculated which show the relation between the present value of lifetime net tax payments and the present value of lifetime GDP per capita. The latter was calculated by discounting back to the year of birth GDP per capita observed over the lifetime taking into account survival probabilities. As shown for Germany, in this case the lines are smoother and the shapes also change somewhat. In the 1970s, the burden now increases for later-born cohorts while it falls in the baseline scenario (graph 3.9). This seems to be related to the negative interest growth differential that prevailed for many years of that decade and which distorts the picture somewhat in the baseline. Our basic conclusion, however, again remains untouched (table 3.4). 


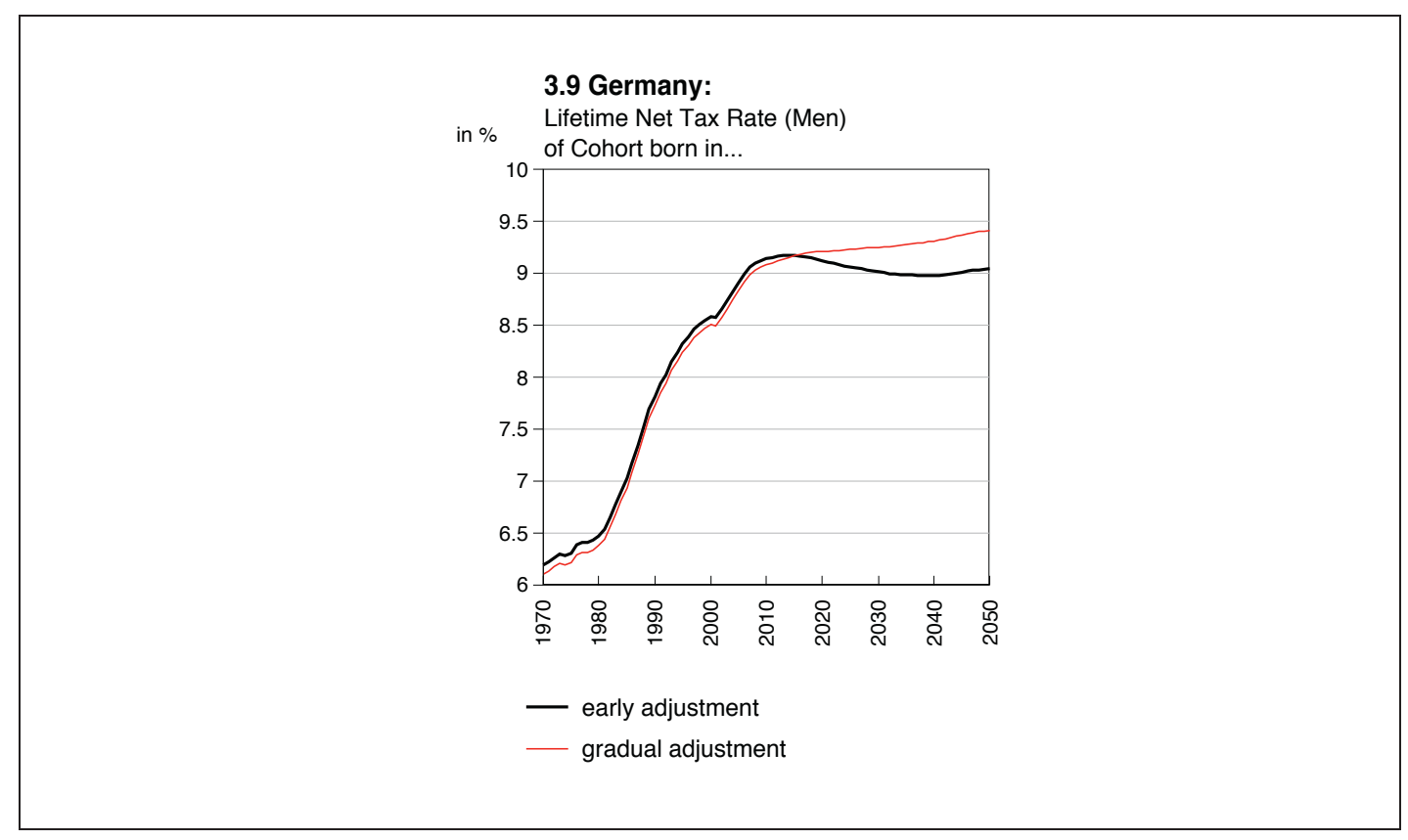

Table 3.4: Intergenerational distribution indicators (lifetime net tax rates)

\begin{tabular}{|c|c|c|c|c|c|c|c|c|}
\hline & \multicolumn{2}{|c|}{$\begin{array}{c}\text { Maximum burden minus } \\
\text { minimum burden* }\end{array}$} & \multicolumn{2}{|c|}{ Standard deviation* } & \multicolumn{2}{c|}{ Coefficient of variation } & \multicolumn{2}{c|}{ Maximum Burden* } \\
\cline { 2 - 9 } & $\begin{array}{c}\text { Early } \\
\text { Adjustment }\end{array}$ & $\begin{array}{c}\text { Gradual } \\
\text { Adjustment }\end{array}$ & $\begin{array}{c}\text { Early } \\
\text { Adjustment }\end{array}$ & $\begin{array}{c}\text { Gradual } \\
\text { Adjustment }\end{array}$ & $\begin{array}{c}\text { Early } \\
\text { Adjustment }\end{array}$ & $\begin{array}{c}\text { Gradual } \\
\text { Adjustment }\end{array}$ & $\begin{array}{c}\text { Early } \\
\text { Adjustment }\end{array}$ & $\begin{array}{c}\text { Gradual } \\
\text { Adjustment }\end{array}$ \\
\hline Germany & 3.0 & 3.3 & 2.2 & 2.2 & 24.1 & 24.6 & 10.2 & 10.4 \\
Women & 3.0 & 3.3 & 2.0 & 2.1 & 24.8 & 25.5 & 9.2 & 9.4 \\
Men & 3.0 & & & & & & & \\
\hline
\end{tabular}

* In euros, deflated by per capita GDP growth

The choice of the discount rate is a tricky question which has often been discussed in generational accounting studies. ${ }^{41}$ In our baseline scenario we used the interest rate assumed by the AWG for future years for discounting (real interest rate of $3 \%$ and inflation of $2 \%$ ). For the past we relied on the yield on long-term bonds issued by the respective government. Thus, the real discount rate is not constant over the whole period. As a first step towards a sensitivity analysis concerning the discount rate it was assumed that the real discount rate was constant from 1970 onwards at 3\% while leaving past inflation untouched. In the result, cohorts' burdens are roughly unchanged compared to the baseline, with the largest changes obviously arising for older cohorts, and lines for the two scenarios cross in the same year (see chart 3.10). Moreover, our basic conclusion again remains unchanged (table 3.5). The second step of the discount rate sensitivity analysis was to change the level of the constant discount rate to $5 \% .42$ This leads to two conclusions. First, cohorts' burden is now lower than in the baseline scenario (or the 'constant 3\% scenario'), especially for cohorts born after the 1990s. Thus, assuming a higher discount rate gives the impression that intergenerational distribution is more even (see the direct comparison of the coefficient of variation with 3\% and 5\% in table 3.5). The second and more important conclusion is that when we assume a constant $5 \%$ discount rate the lines cross more or less at the same time as in the baseline scenario (2023 vs. 2016) and early adjustment still entails a more even distribution (see chart 3.11 and table 3.5).

41 See for example Accardo (1998) for France.

42 This implies that for years after 2008 there is no identity anymore between the discount rate and the interest rate which is used to calculate the government interest burden. 


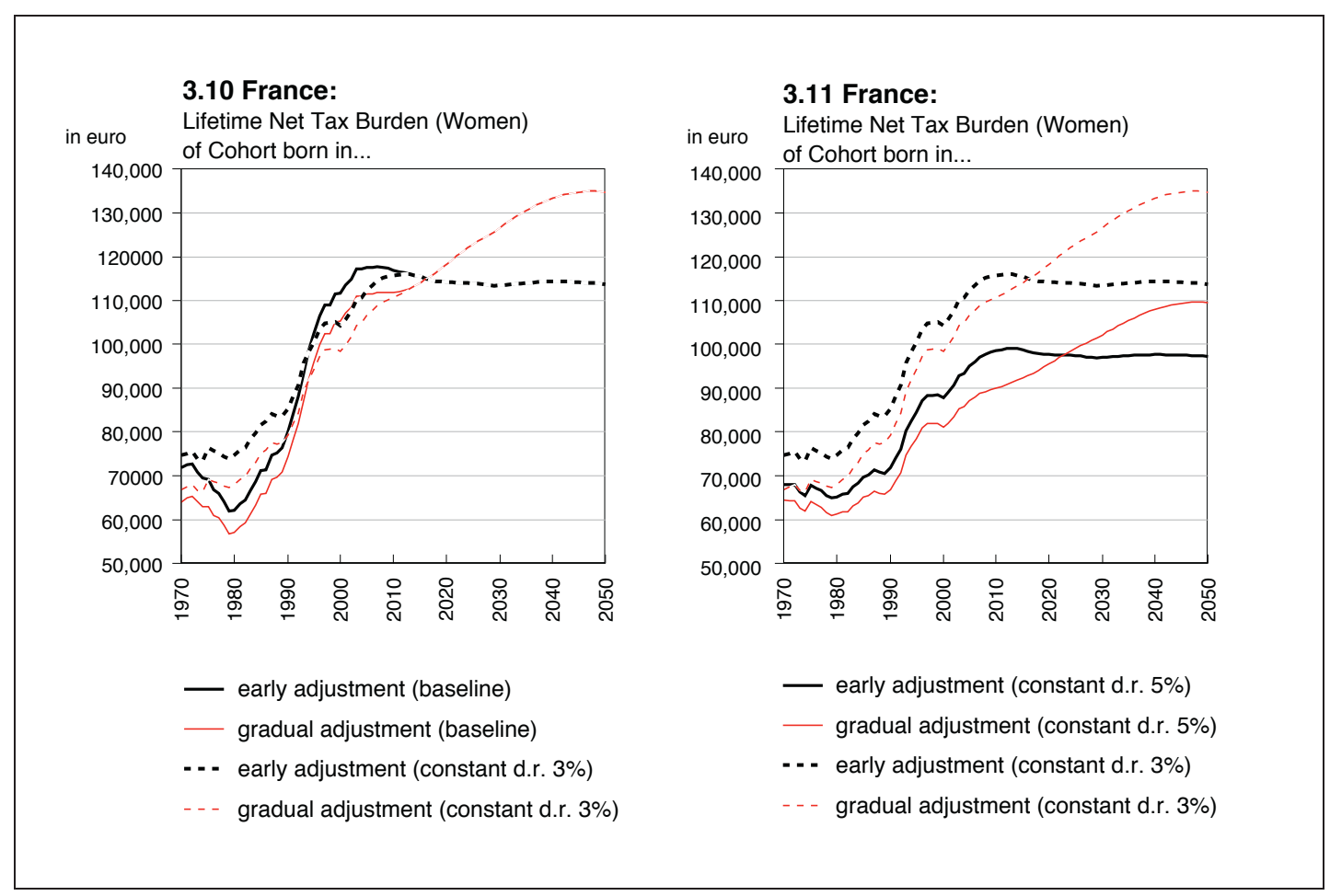

Table 3.5: Intergenerational distribution indicators (constant discount rate from 1970 onwards)

\begin{tabular}{|l|c|c|c|c|c|c|c|c|}
\hline \multirow{2}{*}{ France } & \multicolumn{2}{|c|}{$\begin{array}{c}\text { Maximum burden minus } \\
\text { minimum burden }\end{array}$} & \multicolumn{2}{c|}{ Standard deviation* } & \multicolumn{2}{c|}{ Coefficient of variation } & \multicolumn{2}{c|}{ Maximum Burden* $^{*}$} \\
\cline { 2 - 9 } & $\begin{array}{c}\text { Early } \\
\text { Adjustment }\end{array}$ & $\begin{array}{c}\text { Gradual } \\
\text { Adjustment }\end{array}$ & $\begin{array}{c}\text { Early } \\
\text { Adjustment }\end{array}$ & $\begin{array}{c}\text { Gradual } \\
\text { Adjustment }\end{array}$ & $\begin{array}{c}\text { Early } \\
\text { Adjustment }\end{array}$ & $\begin{array}{c}\text { Gradual } \\
\text { Adjustment }\end{array}$ & $\begin{array}{c}\text { Early } \\
\text { Adjustment }\end{array}$ & $\begin{array}{c}\text { Gradual } \\
\text { Adjustment }\end{array}$ \\
\hline constant d.r. 3\% & & & & & & & & \\
Women & 42,600 & 68,600 & 15,900 & 24,000 & 15.5 & 22.9 & 116,000 & 134,900 \\
Men & 43,000 & 68,800 & 15,900 & 23,900 & 20.3 & 29.9 & 91,500 & 109,400 \\
\hline constant d.r. 5\% & & & & & & & & \\
Women & 34,200 & 48,600 & 12,900 & 16,900 & 14.7 & 19.4 & 99,100 & 109,600 \\
Men & 34,300 & 48,600 & 13,000 & 17,000 & 15.7 & 20.6 & 94,400 & 104,800 \\
\hline
\end{tabular}

Finally, a first small step towards the outcome of a fully-fledged generational accounting exercise can be taken by distributing the burden of the sum of all budget categories not considered to be age-specific by the AWG to persons aged between 20 and 99 years in the scenario with an explicit population forecast for the years after 2050. With the impact of old-age expenditure like pensions, health and long-term care and education for the young determined separately, this is more in line with the age-profiles obtained in generational accounting studies. In this scenario the results change substantially, as illustrated by the case of Germany (chart 3.12). The overall burden is much lower now, backing our earlier note of caution on the reliability of absolute numbers. Moreover, the pattern over cohorts also changes somewhat. The increase for cohorts born after 1980 ends earlier and is significantly less steep. Moreover, the crossing of the lines for early and gradual adjustment occurs almost two decades earlier. However, our basic conclusions not only continue to hold but are actually reinforced (table 3.6). 


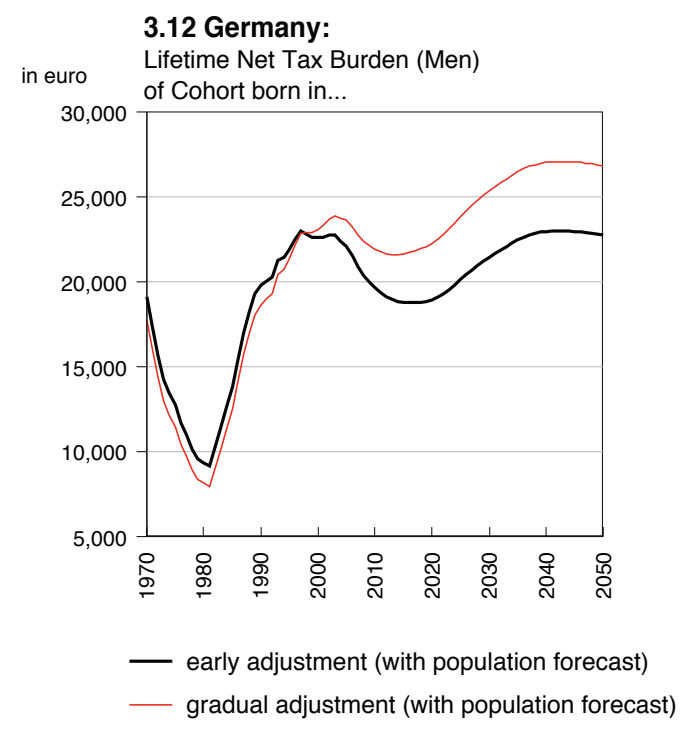

Table 3.6: Intergenerational distribution indicators (budget categories assumed to be nonageing-related by AWG allocated to persons aged 20-99, with population forecast for years after 2050)

\begin{tabular}{|c|c|c|c|c|c|c|c|c|}
\hline & \multicolumn{2}{|c|}{$\begin{array}{c}\text { Maximum burden minus } \\
\text { minimum burden* }\end{array}$} & \multicolumn{2}{|c|}{ Standard deviation* } & \multicolumn{2}{c|}{ Coefficient of variation } & \multicolumn{2}{c|}{ Maximum Burden* } \\
\cline { 2 - 8 } & $\begin{array}{c}\text { Early } \\
\text { Adjustment }\end{array}$ & $\begin{array}{c}\text { Gradual } \\
\text { Adjustment }\end{array}$ & $\begin{array}{c}\text { Early } \\
\text { Adjustment }\end{array}$ & $\begin{array}{c}\text { Gradual } \\
\text { Adjustment }\end{array}$ & $\begin{array}{c}\text { Early } \\
\text { Adjustment }\end{array}$ & $\begin{array}{c}\text { Gradual } \\
\text { Adjustment }\end{array}$ & $\begin{array}{c}\text { Early } \\
\text { Adjustment }\end{array}$ & $\begin{array}{c}\text { Gradual } \\
\text { Adjustment }\end{array}$ \\
\hline Germany & & & & & & & & \\
Women & 21,700 & 27,100 & 10,600 & 12,100 & 26.6 & 29.0 & 47,700 & 52,000 \\
Men & 13,800 & 19,100 & 5,600 & 7,100 & 29.7 & 34.5 & 23,000 & 27,100 \\
\hline
\end{tabular}

* In euros, deflated by per capita GDP growth

Overall, the conclusions derived under the baseline scenario seem to be quite robust with respect to a variety of conceivable variations in underlying parameters and assumptions. From the perspective of intergenerational burden distribution, a rapid adjustment of the primary balance to a sustainable level seems to be preferable to a more gradual approach. Nevertheless, care needs to be exercised when interpreting the results. Data restrictions only allowed us to compare cohorts born since 1970. So a substantial part of the living population could not be included in the analysis. ${ }^{43}$ Moreover, even for this period the underlying data are sometimes of poor quality or had to be estimated. Finally, whether a specific intergenerational distribution is preferred depends on normative presumptions that could be questioned.

\section{Conclusion}

In this paper we analyse (budgetary policy responses to) fiscal sustainability against the backdrop of population ageing. With respect to the budgetary costs of ageing, the projections carried out by the AWG, which was established within the EU's Economic Policy Committee, can be considered as an important reference point. In its 2006 report (EPC and EC, 2006) the AWG estimates, on the basis of a scenario

43 These cohorts might be expected to be less affected by the budgetary consequences of demographic ageing. However, an extension to cohorts born since 1960 for France had little impact on the results. 
taken as a reference, that ageing-related changes in five specific expenditure categories - pensions, health care, long-term care, unemployment and education - can work out at an increase of the expenditure ratio of slightly more than 4\% of GDP for the EU and close to 4.5\% of GDP for the euro area 44 in the 20102050 period. However, such long-term projections typically come with a very large degree of uncertainty.

After a detailed assessment of the projections for the ageing-related expenditure increases for individual countries, we illustrate the upside risks to the AWG's headline projections via a harmonised mechanical exercise that is mainly based upon the sensitivities reported for alternative scenarios considered by the AWG. This exercise incorporates, if applicable, more recent estimates for the further increase in life expectancy by 2050; assumes that the income elasticity of health care expenditure would remain constant at 1.1 throughout the projection period rather than converge to 1 by 2050 as in the AWG headline scenario; and takes into account an increasing importance of the formal sector in the provision of elderly care due to changing family structures and rising female participation rates. It shows, in particular, that plausible alternative assumptions on key parameters in the projections could significantly increase the AWG estimates of ageing-related increases in government expenditure in the 2010-2050 period.

We consider a number of quantitative sustainability indicators to assess the sustainability of public finances in euro area countries against the backdrop of population ageing. While there is no clear-cut theoretical benchmark for fiscal sustainability, the 'conventional wisdom' is that continuously rising and/or extremely high debt ratios are unsustainable. Hence, in practice, quantitative indicators of sustainability gaps typically attempt to measure the fiscal effort required by a certain date to bring the debt ratio back to a sustainable path or level taking into account the projected budgetary impact of ageing and a set of assumptions (e.g. concerning the macroeconomic environment, the implicit interest rate on public debt and deficit-debt adjustments). We argue that the two quantitative indicators that are routinely considered by the EC (and that impose a 60\% and a stable debt ratio by 2050 respectively) may be complemented by other indicators, e.g. imposing a balanced budget by 2050 .

While the exact numbers may differ significantly depending on the sustainability indicator used, the ranking of the countries on the basis of their sustainability gaps is relatively robust. Countries that currently record high fiscal surpluses (e.g. Finland) or have undertaken more important structural reforms to their pensions systems (e.g. Germany, Austria and Italy) tend to experience lower sustainability risks. All indicators confirm that, of the countries considered here (the euro area minus Slovenia, Malta and Cyprus), public finances are currently only sustainable in Finland. All other countries will have to adjust their fiscal policies sooner or later.

Quantitative sustainability indicators such as those considered in this paper typically measure the size of a relatively 'early' adjustment effort aimed at closing the sustainability gap. However, this should not be interpreted as a policy recommendation: the indicators do not imply anything about the appropriateness of such an early adjustment effort to restore fiscal sustainability compared to e.g. that of a more gradual approach. In this connection, it should be stressed that, for many countries, implementing such an early adjustment effort would lead to high surpluses in the coming years and a rapid reduction of public debt ratios (and, in some cases, the building up of net financial asset positions).

The appropriateness of any specific budgetary strategy needs to be assessed on the basis of pre-defined criteria. If intergenerational equity is considered to be a relevant criterion in this respect, generational accounts or, more specifically, the total lifetime contribution of generations born in different years to the government's primary balance may be an important indicator to assess the relative merits of alternative budgetary strategies. In this connection, the intergenerational implications of an 'early' adjustment strategy (an increase in the primary balance by 2015 that is sufficient to absorb the ageing costs and still end up with a balanced budget in 2050) are compared to those of a corresponding 'gradual' approach (that

44 As the Report was published in the beginning of 2006 the EU excludes Romania and Bulgaria while the euro area excludes Slovenia, Cyprus and Malta. 
spreads out the fiscal adjustment over the whole 2008-2050 period) for three countries - Belgium, France and Germany - in this paper.

A number of tentative conclusions can be drawn from the evolution of the total lifetime burden in this empirical exercise. First, a gradual adjustment is typically more favourable for older generations than for generations born after a certain date. Second, this date falls later, i.e. generations that are worse off under the gradual strategy are further away in the future if all generations contribute to the fiscal adjustment than if only generations of working age do. Third, the 'early' adjustment strategy, implying significant government surpluses in the coming years for the three countries considered, generally leads to flatter time profiles of the total lifetime burden - and, hence, may be considered more equitable - than the 'gradual' fiscal adjustment.

While these findings have to be interpreted with caution, not least due to data limitations, they are of particular relevance for the aforementioned upcoming revision of the medium-term objectives for fiscal policy defined in the context of the Stability and Growth Pact. If intergenerational equity is considered to be an important guiding principle in this respect, it could be made operational along the lines suggested above. If our tentative results were confirmed, e.g. with a more complete dataset, and if no further costcutting reforms to pensions and care systems are implemented, an upward revision of these medium-term objectives to significant surpluses may then be warranted for many EU Member States. 


\section{List of references}

Accardo, J (1998), Une étude de comptabilité générationnelle pour la France en 1996, Documents de travail de l'INSEE G9802.

Auerbach, H., J. Gokhale and L. J. Kotlikoff (1994), Generational Accounting: A Meaningful Way to Evaluate Fiscal Policy, Journal of Economic Perspectives, vol. 8, pp 73-94.

Auerbach, H., J. Gokhale and L. J. Kotlikoff (1995), Restoring generational balance in US fiscal policy: what will it take?, Federal reserve bank of Cleveland Economic Review, vol. 31, pp 2-12.

Balassone, Fabrizio and Daniele Franco (2000), 'Assessing fiscal sustainability: a review of methods with a view to $E M U^{\prime}$ in Banca d'Italia, 'Fiscal sustainability', essays presented at the Banca d'Italia workshop held in Perugia, 20-22 January 2000

Barro, R. (1979), On the Determination of the Public Debt, Journal of Political Economy, pp 940-971.

Blanchard, O., J.C. Chouraqui, R.P. Hagemann and N. Sartor (1990), 'The sustainability of fiscal policy: new answers to an old question', OECD Economic Studies, No. 15,

Bonin, H. (2001), Generational Accounting, Theory and Application, Berlin et al.Buiter, W.H., 'A guide to public sector debt and deficits', Economic Policy, No. 1, 1985

Delbecque, Bernard and Henri Bogaert (1994), 'L'incidence de la dette publique et du vieillissement démographique sur la conduite de la politique budgétaire: une étude théorique appliquée au cas de la Belgique', Bureau du Plan, Planning Paper No. 70, November

Domar, E.D., 'The burden of the debt and the national income', American Economic Review, December 1944

Dormont, B., Oliveira Martins, J., Pelgrin, F. and Suhrcke, M. (2007), Health expenditures, longevity and growth, paper presented at the IX FRDB European conference on "Health longevity and productivity", Limone sul Garda (Italy), 26 May

European Commission, 'Public Finances in EMU - 2007', European Economy, Volume 3, June 2007

European Commission, 'Public Finances in EMU - 2008', European Economy, Volume 4, June 2008

European Commission, 'The long-term sustainability of public finances in the European Union', European Economy Volume 4, October 2006

Economic Policy Committee and the European Commission (2006), The Impact of Ageing on Public Expenditure: Projections for the EU25 Member States on Pensions, Health Care, Long-term Care, Education, and Unemployment Transfers, European Economy - Special Report n¹, Brussels.

Franco, D. and T. Munzi (1997), Ageing and Fiscal Policies in the European Union, European Economy Reports and Studies, No. 4, Brussels.

G10 (1998), The macroeconomic and financial implications of ageing populations.

G10 (2005), Ageing and pension system reform: implications for financial markets and economic policies, in OECD, Financial markets trends, no. 2. 
Hauner, D., D. Leigh, and M. Skaarup, (2007), Ensuring Fiscal Sustainability in G-7 Countries, IMF Working Paper 07/187.

Heller, P.S., R. Hemming and P. Kohnert (1986), Ageing and Social Expenditures in the Major Industrialised Countries, 1980-2025, IMF Occasional Paper, No. 47.

Haveman, R. (1994), Should Generational Accounts Replace Public Budgets and Deficts?, Journal of Economic Perspectives, vol. 8, No. 1, pp. 95-111.

Human Mortality Database, University of California, Berkeley (USA), and Max Planck Institute for Demographic Research (Germany). Available at http://www.mortality.org or http://www.humanmortality.de.

Kilponen, J. , Kinnunen, H. and Ripatti, A. (2006) Population ageing in a small open economy - some policy experiments with a tractable general equilibrium model, Discussion Papers, Bank of Finland 28/2006

Knell, M., W. Köhler-Töglhofer, D. Prammer (2006), The Austrian Pension System - How recent reforms have changed fiscal sustainability and pension benefits, Monetary Policy and the Economy Q2/06

Langenus, G. (2006), Fiscal sustainability indicators and policy design in the face of ageing, Working Paper, Research Series, National Bank of Belgium, No. 102, October 2006.

Langenus, G. and B. Eugène (2005), Fiscal policy setting in a forward-looking environment: the case of Belgium, in Les finances publiques: défis à moyen et long termes, papers presented at the 16th Congress Congrès des Economistes belges de Langue française, CIFOP.

Leibfritz, W., D. Roseveare, D. Fore and E. Wurzel (1995), Ageing Populations, Pension Systems and Government Budgets: How Do They Affect Saving?, OECD Working Paper, No. 156, Paris.

Lundback, E., D. Kanda, A. Tieman (2007), Austria: Selected Issues, IMF Country Report No. 07/143 (available at: http://www.imf.org/external/pubs/ft/scr/2007/cr07143.pdf).

Manzke, B. (2002), The long-term sustainability of public finance in Germany - an analysis based on generational accounting, Economic Research Centre of the Deutsche Bundesbank, Discussion Paper 10/02.

Oliveira Martins, J., C de la Maisonneuve (2006), The drivers of Public expenditure on bealth and long-term care: an integrated approach, OECD Economic Studies, vol. 43 (2), pp. 115-154. . Study Group on Ageing (2007), Annual Report,

Pinheiro, M. and Cunha, V. (2007), MISS: A model for assessing the sustainability of public social security in Portugal, Banco de Portugal Occasional Working Paper no. 2.

Raffelhüschen, B. (1999), Generational Accounting: Method, Data and Limitations, in: European Commission (ed.), Generational Accounting in Europe, European Economy - Reports and Studies No. 6.

Rawls, J. (1971), A Theory of Justice, Cambridge.

Rosen, H.S. (1999), Public Finance, $5^{\text {th }}$ ed., Boston et. al.

Visco, I. (2006), Longevity risk and financial markets, keynote speech to the 26th SUERF colloquium, Lisbon, 12-14 october.

Werding, M. and A Kaltschütz (2005), Modellrechnungen zur langfristigen Tragfäbigkeit der öffentlichen Finanzen, ifo Beiträge zur Wirtschaftsforschung, Munich 


\section{European Central Bank Working Paper Series}

For a complete list of Working Papers published by the ECB, please visit the ECB's website (http://www.ecb.europa.eu).

944 "The New Area-Wide Model of the euro area: a micro-founded open-economy model for forecasting and policy analysis" by K. Christoffel, G. Coenen and A. Warne, October 2008.

945 "Wage and price dynamics in Portugal" by C. Robalo Marques, October 2008.

946 "Macroeconomic adjustment to monetary union" by G. Fagan and V. Gaspar, October 2008.

947 "Foreign-currency bonds: currency choice and the role of uncovered and covered interest parity" by M. M. Habib and M. Joy, October 2008.

948 "Clustering techniques applied to outlier detection of financial market series using a moving window filtering algorithm" by J. M. Puigvert Gutiérrez and J. Fortiana Gregori, October 2008.

949 "Short-term forecasts of euro area GDP growth" by E. Angelini, G. Camba-Méndez, D. Giannone, L. Reichlin and G. Rünstler, October 2008.

950 "Is forecasting with large models informative? Assessing the role of judgement in macroeconomic forecasts" by R. Mestre and P. McAdam, October 2008.

951 "Exchange rate pass-through in the global economy: the role of emerging market economies" by M. Bussière and T. Peltonen, October 2008.

952 "How successful is the G7 in managing exchange rates?" by M. Fratzscher, October 2008.

953 "Estimating and forecasting the euro area monthly national accounts from a dynamic factor model" by E. Angelini, M. Bańbura and G. Rünstler, October 2008.

954 “Fiscal policy responsiveness, persistence and discretion" by A. Afonso, L. Agnello and D. Furceri, October 2008.

955 "Monetary policy and stock market boom-bust cycles" by L. Christiano, C. llut, R. Motto and M. Rostagno, October 2008.

956 "The political economy under monetary union: has the euro made a difference?" by M. Fratzscher and L. Stracca, November 2008.

957 "Modeling autoregressive conditional skewness and kurtosis with multi-quantile CAViaR" by H. White, T.-H. Kim, and S. Manganelli, November 2008.

958 "Oil exporters: in search of an external anchor" by M. M. Habib and J. Stráský, November 2008.

959 “What drives U.S. current account fluctuations?" by A. Barnett and R. Straub, November 2008.

960 "On implications of micro price data for macro models" by B. Maćkowiak and F. Smets, November 2008.

961 "Budgetary and external imbalances relationship: a panel data diagnostic" by A. Afonso and C. Rault, November 2008.

962 "Optimal monetary policy and the transmission of oil-supply shocks to the euro area under rational expectations" by S. Adjemian and M. Darracq Pariès, November 2008. 
963 "Public and private sector wages: co-movement and causality" by A. Lamo, J. J. Pérez and L. Schuknecht, November 2008.

964 “Do firms provide wage insurance against shocks? Evidence from Hungary” by G. Kátay, November 2008.

965 “IMF lending and geopolitics” by J. Reynaud and J. Vauday, November 2008.

966 “Large Bayesian VARs” by M. Bańbura, D. Giannone and L. Reichlin, November 2008.

967 "Central bank misperceptions and the role of money in interest rate rules" by V. Wieland and G. W. Beck, November 2008.

968 “A value at risk analysis of credit default swaps” by B. Raunig and M. Scheicher, November 2008.

969 "Comparing and evaluating Bayesian predictive distributions of asset returns" by J. Geweke and G. Amisano, November 2008.

970 "Responses to monetary policy shocks in the east and west of Europe" by M. Jarociński, November 2008.

97I “Interactions between private and public sector wages" by A. Afonso and P. Gomes, November 2008.

972 "Monetary policy and housing prices in an estimated DSGE for the US and the euro area" by M. Darracq Pariès and A. Notarpietro, November 2008.

973 "Do China and oil exporters influence major currency configurations?" by M. Fratzscher and A. Mehl, December 2008.

974 "Institutional features of wage bargaining in 23 European countries, the US and Japan" by P. Du Caju, E. Gautier, D. Momferatou and M. Ward-Warmedinger, December 2008.

975 "Early estimates of euro area real GDP growth: a bottom up approach from the production side" by E. Hahn and F. Skudelny, December 2008.

976 "The term structure of interest rates across frequencies" by K. Assenmacher-Wesche and S. Gerlach, December 2008.

977 "Predictions of short-term rates and the expectations hypothesis of the term structure of interest rates" by M. Guidolin and D. L. Thornton, December 2008.

978 "Measuring monetary policy expectations from financial market instruments" by M. Joyce, J. Relleen and S. Sorensen, December 2008.

979 “Futures contract rates as monetary policy forecasts" by G. Ferrero and A. Nobili, December 2008.

980 "Extracting market expectations from yield curves augmented by money market interest rates: the case of Japan" by T. Nagano and N. Baba, December 2008.

98I "Why the effective price for money exceeds the policy rate in the ECB tenders?" by T. Välimäki, December 2008.

982 “Modelling short-term Interest rate spreads in the euro money market?" by N. Cassola and C. Morana, December 2008.

983 "What explains the spread between the euro overnight rate and the ECB's policy rate?" by T. Linzert and S. Schmidt, December 2008.

984 "The daily and policy-relevant liquidity effects" by D. L. Thornton, December 2008. 
985 "Portuguese banks in the euro area market for daily funds" by L. Farinha and V.Gaspar, December 2008.

986 “The Topology of the Federal Funds Market” by M. L. Bech and E. Atalay, December 2008.

987 "Probability of informed trading on the euro overnight market rate: an update" by J. Idier and S. Nardelli, December 2008.

988 "The interday and intraday patterns of the overnight market: evidence from an electronic platform" by R. Beaupain and A. Durré, December 2008.

989 “Modelling loans to non-financial corporations in the euro area” by C. Kok Sørensen, D. Marqués lbáñez and C. Rossi, January 2009.

990 “Fiscal policy, housing and stock prices” by A. Afonso and R. M. Sousa, January 2009.

991 "The macroeconomic effects of fiscal policy" by A. Afonso and R. M. Sousa, January 2009.

992 "FDI and productivity convergence in central and eastern Europe: an industry-level investigation" by M. Bijsterbosch and M. Kolasa, January 2009.

993 "Has emerging Asia decoupled? An analysis of production and trade linkages using the Asian international input-output table” by G. Pula and T. A. Peltonen, January 2009.

994 "Fiscal sustainability and policy implications for the euro area" by F. Balassone, J. Cunha, G. Langenus, B. Manzke, J. Pavot, D. Prammer and P. Tommasino, January 2009. 
